\title{
Signalling pathways involved in endocrine resistance in breast cancer and associations with epithelial to mesenchymal transition (Review)
}

\author{
SANAA AL SALEH ${ }^{1,2}$, LEYLA H. SHARAF ${ }^{1}$ and YUNUS A. LUQMANI ${ }^{1}$ \\ ${ }^{1}$ Faculty of Pharmacy and ${ }^{2}$ College of Graduate Studies, University of Kuwait, P.O. Box 24923, Safat 13110, Kuwait
}

Received December 30, 2010; Accepted January 31, 2011

DOI: $10.3892 /$ ijo.2011.942

\begin{abstract}
Both de novo and acquired endocrine resistance constitute a major therapeutic problem for treatment of hormone-positive breast cancer. Multiple explanatory mechanisms have been proposed through the study of cellular models which focus principally on receptor tyrosine kinase mediated signalling pathways utilizing SRC, PI3K, MAPK and SMADS. Many of the transducing molecules, particularly nuclear transcription factors such as SNAIL, TWIST, SNAIL2, ZEB, FOXC2, TCF/LEF and GOOSECOID are participants in proliferation as well as invasion and metastasis, involving a process of orchestrated cellular remodeling which is being likened to the process of epithelial to mesenchymal transition that takes place during embryonic development. We review the accumulating evidence that points towards the occurrence of this phenomenon as a consequence of the loss of endocrine control, with both processes being similarly characterized by depletion of cell adhesion proteins, E-cadherin, catenins and cytokeratins, increased association with the extracellular matrix through induction of metalloproteinases, fibronectin and collagen, and a switch to a mobile vimentin-based cytoskeletal structure with loss of apical basal polarity.
\end{abstract}

\section{Contents}

1. Introduction

2. Estrogen receptor action

3. Potential mechanisms of endocrine resistance

4. Epithelial to mesenchymal transition

5. EMT, CSCs and endocrine resistance

6. Reversal of EMT

7. Concluding remarks

Correspondence to: Dr Y.A. Luqmani, Faculty of Pharmacy, Kuwait University, P.O. Box 24923, Safat 13110, Kuwait E-mail: yunus@hsc.edu.kw

Key words: breast cancer, endocrine resistance, epithelial to mesenchymal transition, signal transduction

\section{Introduction}

Endocrine therapy represents the most effective form of treatment for the majority of breast cancer patients whose tumours over-express the estrogen receptor (ER). In addition to ablative procedures (ovariectomy) and administration of antiendocrine agents to inhibit ovarian function, treatment is reliant predominantly upon anti-hormonal agents termed selective estrogen modulators (SERMs). Until recent introduction of agents such as toremifene and raloxifene, tamoxifen has been the mainstay of treatment (1) inducing objective response or disease stabilization in over half of previously untreated metastatic breast cancer patients with $\mathrm{ER}^{+}$tumours (2). Further options include the use of pure anti-estrogens such as fulvestrant (Faslodex) which achieves its effects through receptor degradation, and application of aromatase inhibitors that reduce extra-gonadal peripheral estrogen synthesis from the adrenals and adipose tissue, including the breast. Both types of agents improve relapse-free survival and reduce incidence of contralateral breast cancers in women with early-stage cancer and increase overall survival in patients with advanced disease $(3,4)$. Unfortunately, following initial response to SERMs and second line therapy with aromatase inhibitors, most patients subsequently develop resistance to both classes of drugs and become refractive to further attempts at endocrine manipulation. Added to the de novo resistance in patients whose tumours express levels of ER $<10 \mathrm{fmol} / \mathrm{mg}$ protein, this presents a serious therapeutic problem, particularly in view of the increased aggressiveness of hormone insensitive breast cancers.

\section{Estrogen receptor action}

The classical mode of action of ER is related to the regulation of expression of genes with estrogen response elements (ERE) in their promoters through two distinct transcriptional activation domains; a hormone-independent activating function-1 (AF-1) located at the $\mathrm{N}$-terminus of the receptor with its function regulated by phosphorylation, and the hormone-dependent $\mathrm{AF}-2$, in the ligand-binding domain. In general, both domains have a synergistic effect in mediating positive gene regulation, although AF1 and AF2 can activate some gene promoters independently $(5,6)$. Co-regulatory molecules modulate transcriptional activity of ER through interaction with the ER-ligand complex at the promoter; this activity is specifically enhanced 
by binding to the AF-2 domain of co-activators such as nuclearreceptor co-activator 1 (NCOA1 or SRC1), NCOA2 (TIF2) and NCOA3 (AIB1, TRAM1, RAC3 or ACTR) $(7,8)$. Co-activators enhance ER-driven transcription by several mechanisms that rely on the formation of large complexes including recruitment of histone-acetyltransferase at the promoter site. Binding of co-activators is inhibited by tamoxifen, causing blockade of transcription by AF-2 (9) which would explain its ability to function as a dual antagonist/agonist. Tamoxifen blocks the transcription of AF-2 dependent genes, while acting as an agonist in AF-1-dependent genes $(10,11)$. Interaction with co-repressor proteins such as nuclear-receptor co-repressor 1 and 2, NCOR1 and NCOR2, repress ER-induced transcription by recruiting histone-deacetylase complexes (12-15). Microarray analysis of gene transcription showed that $\sim 70 \%$ of estrogenresponsive genes, that are either transcriptional repressors or anti-proliferative genes, were down-regulated following treatment of MCF-7 cells with estradiol while genes involved in the induction of cell proliferation were up-regulated (16).

ER can also exert its function via a non-classical genomic action that affects gene expression at alternative regulatory DNA sequences such as AP-1 and SP-1. This type of interaction involves co-operation with other transcription factors which include the FOS-JUN complex (17-19). In addition, membrane ER interacts with and/or activates several kinases including the insulin-like growth factor-1 receptor (IGF-1R), SRC, phosphatidylinositol 3-kinase (PI3K), mitogen-activated protein kinase (MAPK), epidermal growth factor receptor (EGFR) and ERBB2 (20-26). Co-activators that can modify ER activity could also be phosphorylated by these cytoplasmic kinases (27-29) which is crucial for the activity of membrane functions of ER which probably have little significance in $\mathrm{ER}^{+}$cells that express low levels of tyrosine kinase receptors such as members of the EGFR family (30).

Many interactions between the genomic and non-genomic pathways occur within the cellular context including ER induction of transforming growth factor $\alpha(\mathrm{TGF} \alpha)$ and amphiregulin expression $(31,32)$. Both bind and activate EGFR leading to activation of MAPK and AKT signalling (33) that can also be activated via direct interaction with EGFR/ERBB2 heterodimers. In addition, specific $G$ proteins are activated by ER binding to caveolin 1 at the cell membrane (34) which in turn leads to the activation of SRC that then activates matrix metalloproteinases which cleave transmembrane precursors of heparin binding-EGF (HB-EGF), an EGFR ligand (35). Estradiol-independent activation of ER through phosphorylation by several intracellular kinases has also been demonstrated $(15,36)$. In response to several cytokines and growth factors such as ligands of EGFR or IGF-1R, pathways including MAPK/ERK, PI3K/AKT, p90rsk and p38 MAPK are activated, leading to ER phosphorylation at key positions in the AF-1 (serines 118 and 167 and threonine 311) and other domains $(27,29,37,38)$.

\section{Potential mechanisms of endocrine resistance}

Better understanding of the pathways underlying intrinsic de novo and acquired resistance to endocrine therapy may point to novel strategies to overcome this problem and facilitate further improvements in breast cancer management.
In addition to possibilities common to the reaction of cells to xenobiotics, resistance might arise as a consequence of loss of expression or function of $\mathrm{ER} \alpha$, including auto-phosphorylation (39), modulation by activation of transmembrane tyrosine kinase receptors and interaction between downstream signal transduction pathways $(40,41)$. Loss of ER expression is likely to be the most frequent mechanism for de novo resistance to tamoxifen but is insufficient to explain acquired resistance (42). A second ER (ER $\beta)$ that is interactive with ER $\alpha$, but has different transcriptional activity, is generally considered to be an anti-proliferative factor (43-45) but its role in resistance still remains unclear and will not be discussed here. All reference in this review to ER should be assumed to mean ER $\alpha$ unless otherwise indicated. Fig. 1 lists some of the molecules that have been implicated in proliferation of resistant cell lines as well as those found to be over-expressed in ER ${ }^{-}$tumours. These are discussed below.

Co-activators and co-repressors. The SRC family of coactivators has a wide spectrum of effectors including nuclear receptors and transcription factors that include nuclear factor- $\kappa \mathrm{B}(46)$ that has been implicated in endocrine resistance. Several members of this family, SRC-1/NCOA-1, SRC-2/ GRIP1/TIF2/NCOA-2 and AIB1/SRC-3/RAC3/ACTRp/CIP share a common domain structure and functions (8). The role of SRC-1 in the agonistic action of tamoxifen in the uterus is a clinically significant example of the specificities of SRCS which occur only on non-consensus responsive sites (15).

The other interesting member of the SRC family is AIB1, which is over-expressed in $>50 \%$ of breast tumours, with gene amplification in $\sim 5-10 \%$ (48-50). The mouse AIB1 homologue SRC-3 shows tissue-specific expression and is essential for normal mammary gland development. The diversity of the co-activator family members is also demonstrated by gene knockout studies that show a distinct physiological role of SRC-3/AIB1 that is different from that of SRC-1 (51). In cultured MCF-7 cells, AIB1 is also highly up-regulated and reported to be necessary for their growth (52). It enhances tamoxifen agonistic activity (53) and may have a potential role in endocrine resistance. Over-expression and increased phosphorylation of A1B1 leads to constitutive ER-mediated transcription, which confers resistance in vitro and in xenograft models $(39,54)$ and is associated with reduced patient responsiveness to tamoxifen (55). It is still unclear how phosphorylation activates ER co-activators. Recent studies suggest that it can enhance their nuclear sub-localization and interaction with ER (56) and may directly increase their own acetyl-transferase activity or stimulate their ability to recruit other transcriptional co-activators or integrators to the receptor complex (28).

Another co-activator, PELP1, confers tamoxifen resistance in its cytoplasmic localization (57). It functions as a scaffold protein that modulates ER activation of SRC and the ERK family kinases. It also promotes estrogen activation of PI3K31. Other co-activators found to be implicated in endocrine resistance are AP1 and SP1 (58-60).

The SRC substrate BCAR1 (also known as CAS) is a focal adhesion adaptor protein that activates proliferative, survival and invasion pathways and can induce tamoxifen resistance when over-expressed in vitro (61). Indeed, BCAR1-overexpressing breast cancers are less responsive to tamoxifen (62). 


\begin{tabular}{|c|c|}
\hline GROWTH F & \\
\hline FGF, EGF, TGFa, IGFII & \\
\hline RTKs & \multirow{6}{*}{$\begin{array}{l}\text { ER-VE TUMOURS } \\
\text { EGFR/ERBB2 } \\
\text { HGF/MET } \\
\text { STS,STMN, VIM } \\
\text { S100A4, cadherin 3 } \\
\text { cathepsin B, L } \\
\text { PLAU, serpine } \\
\text { AKT3, SNAIL } \\
\text { TIMP1, tenascin c } \\
\text { cyclin D, E1 }\end{array}$} \\
\hline $\begin{array}{l}\text { FGFR, IGF1R } \\
\text { EGFR/ERBB2 }\end{array}$ & \\
\hline CELL CYCLE & \\
\hline $\begin{array}{l}\text { cyclin D, E1, BCL2, } \\
\text { MYC, p21, p27, RB }\end{array}$ & \\
\hline RTK SIGNALLING & \\
\hline $\begin{array}{l}\text { MAPK, MEK, ERK } \\
\text { PI3K, AKT, SRC, BCAR1 }\end{array}$ & \\
\hline
\end{tabular}

ER-ASSOCIATED TRANSCRIPTION FACTORS /CO-ACTIVATORS

AP1, NFKB, NCOA1, NCOA3, PELP1, CBP

Figure 1. Groups of molecules whose activity is related to tamoxifen resistance or found to be over-expressed in ER- tumours. Note the considerable overlap with molecules reported to be involved in EMT.

BCAR1 binds and activates SRC with consequent phosphorylation of the SRC substrates EGFR and signal transducer and activator of transcription factor $5 \mathrm{~B}$, and effects on downstream signalling pathways (63). However, the ability of BCAR1 to confer anti-estrogen resistance may not require interaction with SRC. The putative guanine nucleotideexchange factor BCAR3, which synergizes with BCAR1 to activate SRC, causes tamoxifen resistance in vitro (64). BCAR3 also activates RAC and p21- activated kinase 1 which is implicated in tamoxifen resistance through ER phosphorylation (65).

The recruitment of co-repressors normally involves binding of antagonists such as tamoxifen to the ER $(7,14)$. Although in vitro tamoxifen resistance is thought to be associated with reduced co-repressor levels, no clinical data currently support this hypothesis $(30)$. Some studies $(66,67)$ suggest that, at least in cultured cells, modulation of the agonist/antagonist activity of tamoxifen can be affected by the differential expression or activity of co-activators and co-repressors. Progesterone and glucocorticoid receptor-mediated transcription that are provoked by their own selective receptor modulators can also be modified by co-activator/co-repressor ratio (68). This ratio was also reported to confer hyper or hyposensitivity to their ligands (69) providing a possible explanation for some clinical tamoxifen resistance and the tissue-specific actions of SERMs (15).

Tamoxifen metabolism. The metabolism of tamoxifen has also been implicated in intrinsic resistance to therapy. Plasma concentrations of tamoxifen metabolites can be affected by genetic polymorphisms in genes of tamoxifen-metabolizing enzymes. In tamoxifen-treated patients, a higher risk of disease relapse has been associated with women with selective cytochrome p450 2D6 (CYP2D6) genotypes. Indeed, CYP2D6 status may be used to identify patients who would benefit from tamoxifen therapy and those tamoxifen-treated patients who should not be co-administered potent CYP2D6 inhibitors (70).

Kinase activated growth pathways. It is increasingly recognised that growth factor stimulated pathways play a central role in acquired and intrinsic resistance to endocrine agents $(71,72)$. Hiscox et al (73) have shown that tamoxifen resistance in MCF-7 cells is associated with elevated expression and activation of components of the EGFR signalling pathway (EGFR, ERBB2, TGF $\alpha$, MAPK). The same authors noted that this change was accompanied by enhanced cell motility and matrix invasion. Cross-talk between the pathways adds to the already existing complexity of resistance. Some models have predicted that increased signalling through growth factor receptor pathways could promote the ER pathway, which would itself re-activate growth factor signalling leading to further transcriptional activation of estrogen-responsive genes and enhanced cross-talk. The effect of tamoxifen in inhibiting cell growth might itself be inhibited through the actions of increased growth factor signalling which would contribute to endocrine resistance. This mechanism has important clinical implications as many tyrosine kinase inhibitors used in ERBB2-targeted therapy such as trastuzumab and the EGFR tyrosine kinase inhibitor, gefitinib, might be useful agents to prevent tamoxifen resistance (73). Erlotinib (Tarceva) and imatinib (Gleevec) that also preferentially target EGFR have been therapeutically effective in treating several malignancies including small cell lung and pancreatic cancers. ER interacting with several kinases, including that of IGF-1R and the p85 regulatory subunit of $\mathrm{PI} 3 \mathrm{~K}$ via adaptor proteins, SRC and SHC, result in different cell survival and proliferative signals via the AKT and MAPK pathways.

EGFR/ERBB2 activated pathways. Some studies suggest that ER expression and/or function could also be reduced by the activation of growth factor signalling. For example, MCF-7 cells treated with EGF, IGF-I, TGF $\beta$ or phorbol myristate acetate had lowered ER mRNA and protein (74-77) and increased signalling through EGFR, PI3K/AKT, PKA and PKC.

The transcriptional activity of ER has been shown to be repressed by heregulin which can activate both EGFR and ERBB2 through formation of heterodimers with either ERBB-3 or ERBB-4 (78,79). Transfection of constitutively active ERBB2, RAF1 or MEK results in significant reduction in expression of ER mRNA and protein and estrogen-regulated genes, resulting in development of estrogen independence (80-83). Cumulatively, these data suggest that growth factor signalling contributes to transcriptional repression of ER expression in breast cancer cells, resulting in endocrine resistance. A 5-10-fold increase in mRNA and protein expression of ERBB2 and EGFR has been noted in tamoxifen resistant MCF-7 cells (84). ERBB2 is frequently over-expressed in $20-30 \%$ of breast cancers and is associated with a more aggressive phenotype (85). Furthermore, this increased expression also appears to activate EGFR/ ERBB2 heterodimers and to cause increased phosphorylation of MAPK, AKT and nuclear ER on serine residues 118 and 167 (86-89). EGFR/ERBB2 signalling was reported to be involved in cellular models with acquired tamoxifen resistance (72) and its inhibition by gefitinib or trastuzumab resulted in 
growth suppression of these cells (90). Furthermore, the addition of EGF-like peptides increased phosphorylation levels of ER and ER-induced transcription which was blocked by treatment with gefitinib. Increased synthesis of TGF $\alpha$ and amphiregulin that maintains the EGFR/ERBB2 autocrine loop operating in tamoxifen-resistant cells was a result of this enhanced transcriptional activity of ER (87). Adapted resistance to fulvestrant in MCF-7 cells was also correlated with increased EGFR signalling (91). However, fulvestrant resistance to aromatase inhibitors can also be mediated by up-regulation of the ERBB2/HER2 pathway (42). Patients presenting with acquired resistance to tamoxifen showed increased levels of ERBB2 and increased activation of p38-MAPK (92) which was only observed in MCF-7 xenografts subjected to combined estrogen deprivation and tamoxifen, but not with estrogen deprivation alone. In addition, a phase-II clinical trial on tamoxifen-resistant advanced breast cancer patients treated with gefitinib showed beneficial effects of anti-EGFR agents (93). Increased levels of EGFR and MAPK activity was also associated with the acquired endocrine resistance of long-term tamoxifen treated MCF-7 cells (94).

The X-linked tumour suppressor forkhead box P3 and the zinc finger transcription factor GATA4 can repress ERBB2 expression, even in a cell line with $\sim 10$-fold amplification of ERBB2, and their expression is negatively correlated with ERBB2 expression in breast cancer $(95,96)$. In addition, ER-mediated repression of ERBB2 was reported to be dependent on competition between the paired-domain transcription factor PAX2 and the ER co-activator NCOA3 for binding and regulation of ERBB2 transcription and, in turn, tamoxifen responsiveness (97). However, increased PAX2 expression and consequent repression of ERBB2 was associated with increased survival following tamoxifen treatment, and loss of PAX2 expression in the presence of increased NCOA3 expression predicted a poor outcome (97), indicating that this mechanism is of direct clinical relevance.

High levels of AIB1 can greatly reduce the antagonist effects of tamoxifen in tumours that over-express growth factor receptors such as ERBB2. A1B1 is phosphorylated and activated by several signalling kinases, including p42/44 MAPK that can be activated by ERBB2 itself hence forming a link between ERBB2 and A1B1 in breast cancer progression (28). This suggests that relatively high levels of co-activators such as A1B1 can cause a lower response to tamoxifen therapy in tumours expressing them caused by the increased estrogen agonistic activity of the tamoxifen-bound ER (98). It was also reported that following treatment of the ERBB2-overexpressing MCF-7/HER2-18 cells with tamoxifen, co-activators such as AIB1 were recruited to the ER-tamoxifen complex more than co-repressors. In these cells, tamoxifen tends to act as an agonist in the presence of low levels of estrogen. EGFR/ ERBB2 signalling is also activated promoting the activation of both MAPK and AKT signal transduction pathways (26) which would phosphorylate and functionally activate both ER and AIB1. These phenomena can be blocked by treatment with gefitinib and often result in inhibition of cell growth, suggesting the possible involvement of EGFR/ERBB2 signalling in the growth-promoting activity of tamoxifen in these cells. Interestingly, gefitinib had little effect on estrogeninduced growth which is consistent with clinical observations indicating that co-expressing ERBB2 and AIB1 results in a poor outcome if associated with tamoxifen treatment (55). Furthermore, patients that express either ERBB2 or EGFR are relatively resistant to tamoxifen but are sensitive to aromatase inhibitors $(99,100)$. A shorter disease-free survival in patients presenting with high levels of A1B1 was observed after tamoxifen administration as an adjuvant treatment (55). On the other hand, untreated patients presenting with high levels of A1B1 had a better outcome (30).

IGF-1R signalling is also involved in tamoxifen-resistant cells, with IGF-II induced increase of IGF-1R phosphorylation and subsequent EGFR activation $(101,102)$. Tamoxifen treatment of MCF7 cells reduces both total and activated IGF-IR. A specific IGF-1R inhibitor, as well as an IGF-II neutralising antibody, can not only reduce ER phosphorylation and tumour proliferation but also affect EGFR signalling events; but EGF mediated actions are not blocked. Although unclear in breast cells, in some tumours IGF-1R can induce metalloproteinasedependent release of heparin-EGF and amphiregulin to transactivate EGFR.

De-regulation of ERBB2, EGFR and IGF-1R pathways could occur as a result of genetic or epigenetic modifications, such as amplification of ERBB2, activating mutations in PIK3CA, which encodes a catalytic subunit of type I PI3Ks, and loss of heterozygosity or methylation of PTEN, a tumour suppressor that inhibits the PI3K pathway (63). In other cases, this de-regulation reflects aberrations in upstream regulators, such as the activation of AKT in association with the loss of PTEN expression or over-expression of ERBB2 $(63,103)$ and activation of IGF-1R and ERBB3 following the loss of PTEN (104).

PI3K cell survival pathway. Non-genomic activity of ER may be influenced by the PI3K pathway that is activated by growth factor induced tyrosine kinase receptor phosphorylation. ER displays ligand-dependent binding to the p85a regulatory subunit of PI3K, resulting in the activation of AKT which increases cellular proliferation and decreases apoptotic responses $(105,106)$ and which is the target of several other receptor stimulated pathways through IGF-1R, EGFR and ERBB2 (107). PI3K also causes ER phosphorylation at serine-167 by AKT activation resulting in ligand-independent activation (29). In one study, it was shown that addition of the PI3K pathway inhibitor LY294002 enhanced the pro-apoptotic effects of tamoxifen, primarily in the cell line with the maximum endogenous levels of AKT activity (106). MCF-7 cells transfected with AKT show a reduction in tamoxifen induced inhibition of cell growth (29), supporting the notion that high expression of AKT is associated with tamoxifen resistance.

Stress-activated protein kinase/c-JUNNH2 terminal kinase pathway. ER can interact with the stress-activated protein kinase/c-JUNNH2 terminal kinase pathway either by binding with the AP-1 transcription complex, by dimerization of JUN and FOS family members that bind to AP-1 response elements on DNA (108), or by direct p38 MAPK activation. AP-1 transcriptional activity is enhanced by increased abundance of any of its components or by the JUN NH2-terminal kinases (JNKs) or stress-activated protein kinases that are induced by cellular insults such as oxidative stress (109). One study reported that increased AP-1 DNA binding is associated with the development of tamoxifen resistance in MCF-7 (110). This 
was also reported in a study of 30 primary human breast tumours with acquired tamoxifen resistance, compared with 27 untreated controls (58). The agonistic effects of tamoxifen at AP-1 sites can also be induced by tamoxifen induction of intracellular oxidative stress that leads to the activation of JNK and increased AP-1 activity $(59,111)$. New and Han (112) showed that activation of the p38 MAPK pathway, that targets further protein kinases and transcription factors, occurred in response to various extracellular stimuli including cytokines, growth factors, chemical and physical stress. Other studies showed that 4-hydroxytamoxifen resistant cell lines displayed a non-active $\mathrm{p} 38$ signalling that was directly related to apoptosis inhibition $(113,114)$.

Keratinocyte growth factor pathways. It has been suggested that keratinocyte growth factors (KGFs) are important regulatory factors acting as estromedins for the stimulation of breast cancer cell growth. KGF also stimulates aromatase activity, promoting conversion of androgens to estrogens in primary cultured human breast cells. KGF might increase endocrine resistance via reduction in ER, PR and PTP $\gamma$ as well. The functional analysis of KGF-13 suggests possible applications of short receptor-binding peptides derived from intact $\mathrm{KGF}$ as therapeutic agents (115).

NOTCH pathway. The NOTCH pathway is implicated in both cell fate in the normal human mammary gland (116) and regulation of cancer stem cells (CSCs) in both ductal carcinoma in situ (117) and invasive carcinoma of the breast $(118,119)$. Luminal type breast cancers express low levels of NOTCH and ERBB2 but high levels of ER compared to basal types, which show the opposite pattern (120). Estrogen signalling down-regulates the NOTCH pathway; estradiol-induced reduction of NOTCH 1 and 4 in both T47D and MCF7 cells which could be abrogated by either tamoxifen or fulvestrant (120). In a mouse xenotransplantation assay using BT474 cells, tumours were treated with tamoxifen alone or in combination with a $\gamma$ secretase inhibitor (121). Combination therapy was significantly superior to the use of tamoxifen alone and the authors concluded that tamoxifen antagonism of the estrogen stimulus leads to the re-activation of the NOTCH signalling pathway promoting proliferation and survival.

Cell cycle regulators. Data from experimental model systems indicate that anti-estrogens are both cytostatic and cytotoxic. Neoadjuvant endocrine therapy leads to decreased cell proliferation (122), and in cell culture anti-estrogen treatment leads to a G1 specific cell cycle arrest and a consequent reduction in growth rate (123). The molecules involved in the antiestrogenic effects on cell cycle progression have central roles in the control of G1 phase progression downstream of other growth factors, as well as estrogen. Aberrant expression of several such estrogen and anti-estrogen targets confers resistance in vitro and is associated with reduced tamoxifen responsiveness in patients. Over-expression of MYC, cyclin E1, D1 or its splice variant D1b, or the inactivation of the Rb tumour suppressor, an important substrate for cyclin-dependent kinases (CDKs) that are active in G1 phase, and the decreased expression of the CDK inhibitors p21 or p27, results in decreased anti-estrogen sensitivity in vitro (124-132). The over-expression of MYC and consequent tamoxifen resistance is accompanied by transcriptional repression of CDKN1A
(133), relieving the inhibitory effect of p21 on cyclin E1-CDK2 complexes. Cyclin D1 over-expression leads to an increased abundance of cyclin D1-CDK4 complexes which indirectly activate cyclin E1-CDK2 by sequestering p21 and p27 $(126,134)$, and to the activation of cyclin E2-CDK2 by increased transcription of CCNE2 which encodes cyclin E2 (135). In addition to its cell cycle regulatory role, cyclin D1 interacts with several transcription factors, including ER and STAT3 (136). Moreover, tamoxifen induces cyclin D1 binding to ER at the expense of cyclin D1-STAT3 binding, activating both STAT3 and ER. This is an additional mechanism by which cyclin D1 over-expression can affect tumour response to tamoxifen (137). Therefore, MYC and cyclin D1 overexpression can potentially affect anti-estrogen sensitivity at several levels and this is associated with tamoxifen resistance in patients $(138,139)$. There is also more limited evidence for a relationship between over-expression of cyclin E1, Rb inactivation and reduced expression of p27 and clinical response (130,138-140). Over-expression of MYC, cyclin D1 and cyclin E1 in breast cancers is at least two to three times more common than amplification of the corresponding genes (138). $\mathrm{Rb}$ inactivation is also more common than its deletion or mutation (130) possibly due to activation of upstream mitogenic signalling pathways and de-regulation of transcriptional regulators including members of the E2f family. The gene encoding p27, CDKN1B, is rarely mutated or deleted in breast cancer, but its expression is frequently reduced by oncogenic activation of mitogenic signalling (for example by ERBB2 over-expression or SRC activation) with increased degradation (140).

The microRNAs (miRNAs) miR-221 and miR-222 reduce p27 expression and confer resistance to tamoxifen, although the precise mechanism is unclear, as these miRNAs also reduce ER expression and are over-expressed in ERBB2-overexpressing breast cancer $(141,142)$. There is conflicting data on the relationship between p21 expression and outcome in breast cancer (138). The role of p21 in tamoxifen response has not been studied extensively, although the ERBB2 repressor forkhead box P3 is essential for p21 expression (143) and there is some evidence for p21 de-regulation in cancers with ERBB2 over-expression or AKT activation (139). The latter results in the mis-localization of $\mathrm{p} 21$ to the cytoplasm, a phenomenon associated with poor response to tamoxifen (144).

Targeting CDK10 also causes resistance to tamoxifen and other endocrine agents in vitro. Iorns et al (145) observed that CDK10 silencing increased ETS2-driven transcription of c-RAF. This led to MAPK pathway activation and loss of tumour cell dependency on estrogen signalling suggesting that CDK10 could be an important determinant of endocrine resistance. Furthermore, patients with $\mathrm{ER}^{+}$tumours that expressed low levels of CDK10 were associated with poor clinical response to tamoxifen.

Apoptosis. Treatment with high concentrations of anti-estrogens, estrogen withdrawal or aromatase inhibitor treatment of cells transfected with aromatase leads to the activation of the cellular stress response and apoptosis in breast cancer cells $(146,147)$. The mechanisms are not well defined, but several molecular consequences that promote apoptosis have been documented, including regulation of BCL-2 family members and increases 
in the apoptotic second messenger ceramide. Cross-talk between the apoptotic effects of anti-estrogens and the tumour necrosis factor (TNF) pathway, as well as anti-estrogen effects on survival signalling through the PI3K-AKT, NF- $\kappa \mathrm{B}$ and interferon pathways is also likely to contribute to anti-estrogenmediated apoptosis (148). Other observations indicate that autophagy is a mechanism of cell survival in breast cancer cells that are resistant to apoptotic concentrations of tamoxifen (149).

It has been difficult to establish the role of apoptosis in the clinical setting. Neoadjuvant studies have yielded conflicting data and have been limited by small patient numbers and the methodological difficulties of measuring apoptosis in vivo (150). As tumour growth reflects the balance between cell proliferation and cell death, disruption of this balance is expected to affect clinical response. There is accumulating evidence for the increased expression of anti-apoptotic molecules, for example BCL-2 and BCLXL, and decreased expression of pro-apoptotic molecules such as BAK, BIK and caspase 9, in attenuated responses to tamoxifen (148). Although many of these responses are probably consequences of the activation of survival signalling through the PI3K-AKT pathway, as a result of over-expression of receptor tyrosine kinases and increased 'non-genomic' signalling from cytoplasmic ER, other pathways have been reported. For example, increased DNA-binding and transcriptional activity of $\mathrm{NF}-\kappa \mathrm{B}$ are features of tamoxifenresistant cells, and tamoxifen sensitivity can be restored by parthenolide, a specific NF- $\kappa \mathrm{B}$ inhibitor $(60,148)$. Tamoxifen insensitivity in vitro is also associated with the down-regulation of IRF1, an interferon-responsive putative tumour suppressor that binds $\mathrm{NF}-\kappa \mathrm{B}$ and is essential for apoptosis. Furthermore, over-expression of a splice variant of human X-box-binding protein 1 , a transcription factor that controls the unfolded protein response, is also associated with tamoxifen resistance in vitro and poor survival in patients with breast cancer treated with tamoxifen (151-153). Correlation of NF- $\kappa \mathrm{B}, \mathrm{XBP1}$ and IRF1 expression in patients with breast cancer (154) suggests that these molecules may function in a common pathway (155). Fig. 2 illustrates the involvement of some of the signalling pathways that have been described in the preceding sections.

\section{Epithelial to mesenchymal transition}

At the leading edge of invasiveness and metastasis, solid tumours that are epithelial in origin, start to lose their characteristic cell-cell adhesive structures, change their polarities and undergo extensive re-organization of their cytoskeletal systems. They switch expression from keratin-to-vimentin type intermediate filaments, become isolated, motile, and resistant to anoikis with enhanced survival. They gain resistance to cytotoxic drugs and acquire the ability to invade neighbouring tissue and penetrate into the vasculature to metastasize. This has been reported with non-small cell lung carcinomas, pancreatic, colorectal, and hepatocellular cancers (156). This type of behaviour is identified with cells undergoing epithelialto-mesenchymal transition (EMT) (157), a phenomenon that was originally defined as the cellular remodelling that occurs during heart morphogenesis and was first observed and recorded by Greenburg and Hay (158). It is seen as a series of changes from characteristic cobblestone-like epithelial morphology to a spindle, fibroblast-like shape with migratory protrusions. Carcinomas of epithelial origin may acquire a mesenchymallike state in order to facilitate their migration and invasion. This is illustrated in Fig. 3 showing that the morphological and behavioural changes are accompanied by a distinct change in the gene expression profile. When the migrating metastatic cells reach their secondary site of carcinogenesis, presumably in order to survive in the local milieu, the cancer cells revert to their epithelial state to form organized tumourigenic nodules, a reverse process referred to as epithelial to mesenchymal transition (MET). During EMT and MET, a bimodal communication exists between the host fibroblasts, extracellular matrix/basement membranes, and the immune cells.

Although evidence supporting the occurrence of EMT is slowly growing from in vitro data such as the pathway blockade by agents like NFא $\beta$ and SMADs $(159,160)$, it seems to have gone largely unnoticed during routine histological examination of tissue biopsies. This has led to much scepticism among some pathologists about whether this process actually occurs in vivo (161-163) or is just an in vitro phenomenon resulting from manipulation of cells in an artificial environment. Nevertheless, the accumulating molecular evidence is presenting a strong argument for closer cytological as well as molecular examination of the process of metastasis.

Genes that are activated in EMT during carcinoma progression and metastasis are also active in early embryogenesis, tissue morphogenesis, and wound healing, suggesting that EMT involves a re-activation of these developmental events during tumour progression. This process of de-differentiation is carried out through a series of transcriptional re-programming steps involving the participation of a number of transcription factors such as ZEB1/TCF8, SNAIL, ZEB2, SNAIL2, E12/E47, FOXC2, GOOSECOID and TWIST (164). This is followed by the activation of abnormal survival signals via receptors such as platelet derived growth factor receptor (PDGFR), fibroblast growth factor receptor (FGFR), cMET, transforming growth factor $\beta$ receptor (TGF $\beta R$ ), IGF-IR, human growth factor receptor (HGFR) and EGFR and regulatory kinases such as PI3K, AKT and mTOR.

The evidence for EMT-associated tumour motility is supported by network signalling pathways mediated by fluctuating levels of TGF $\beta$, EGF, PDGF, ERK/MAPK, $\beta$-catenin, SMADS, RAS, c-FOS, integrins $\beta 4$ and $\alpha 5$, and most importantly the dissolution of cell-cell junctions mediated by SNAIL, SNAIL2 and E2a transcription factors (165).

The actual triggers of EMT in breast cancer are not yet known. MCF10A cells, an immortalised line derived from spontaneous transformation of normal epithelial cells obtained from reduction mamoplasty, have been seen to undergo EMT in response to multiple factors including a combined expression of H-RAS and ERBB2 in 3D marginal culture, undergoing monolayer wounding enhanced by EGF and IGF-IR overexpression, introduction of constitutively active p65 subunit of NF- $\kappa \mathrm{B}$, chronic exposure to TNF- $\alpha$ and expression of $\mathrm{Rb}$ suppressor associated protein 46 (RbAp46/RbBP7) $(166,167)$.

Molecular profiling of 'triple-negative' (ER-, $\left.\mathrm{PR}^{-}, \mathrm{ERBB} 2^{-}\right)$ metaplastic breast tumours indicates an enrichment of stem cell-like and EMT markers (168). Data from c-MYC initiated murine tumours indicate that whilst EMT may not be an 


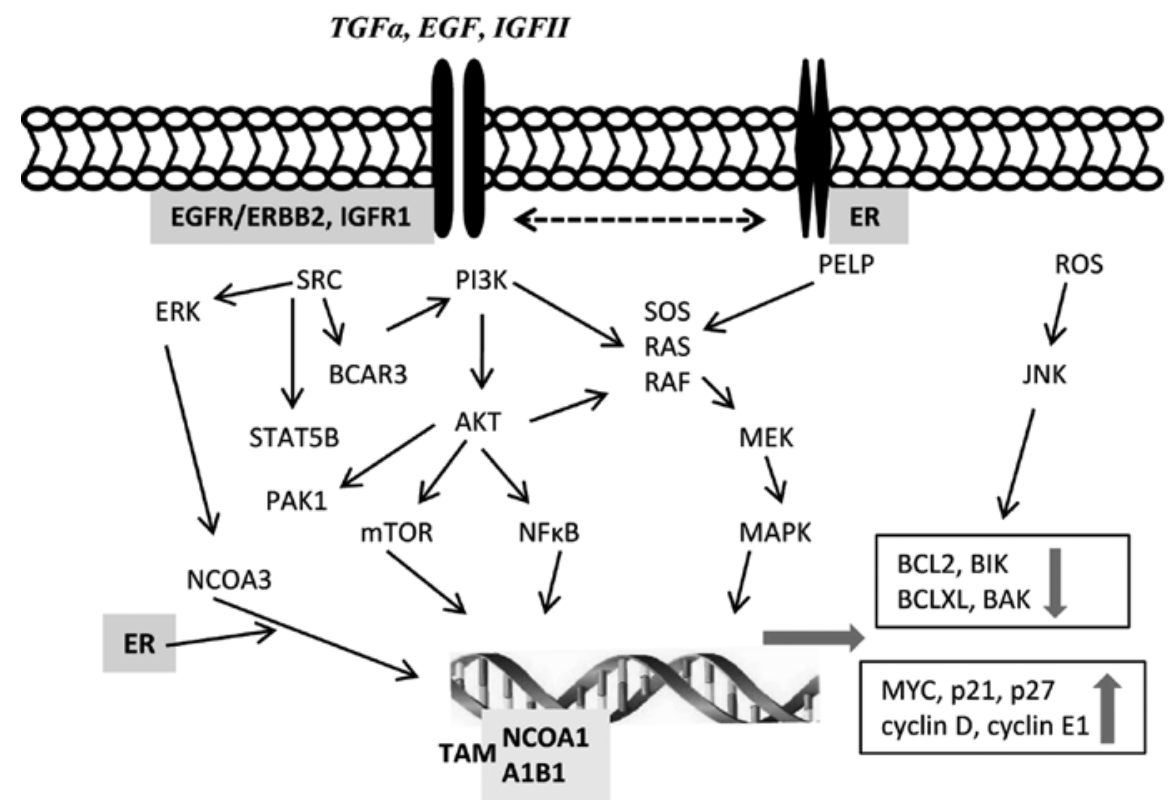

Figure 2. Pathways postulated to be involved in growth of endocrine-resistant cells as discussed and referenced in the text. Cross-talk between membrane bound ER and receptor tyrosine kinases is thought to elicit downstream transcriptional complexes at target gene promoter sites including those with A1B1 and NCoA1 which result in ligand independent ER and or tamoxifen agonist activity leading to increased cell cycle regulators and decrease in apoptotic mediators.

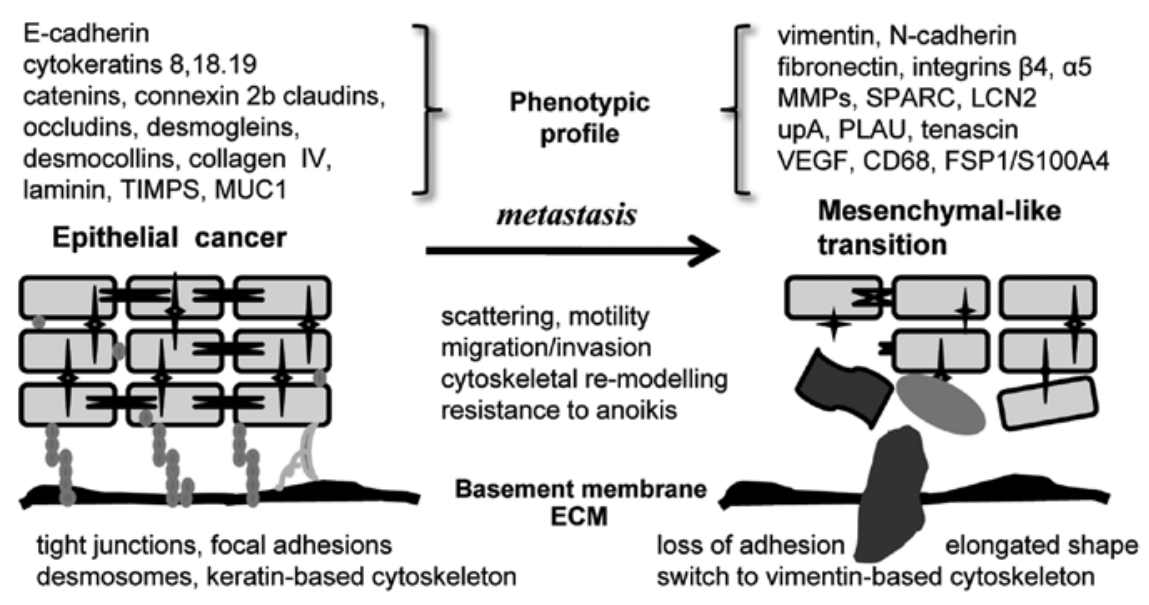

Figure 3. Epithelial to mesenchymal transition. Morphological changes initiated through a series of cell signalling events lead to loss of epithelial apical basal polarity, detachment from the tumour and a remodelling of the cellular architecture allowing individual cells to gain motility and adopt a molecular phenotype resembling that of mesenchymal cells. Examples of the most commonly reported genes found to be over-expressed in the two types of cells is shown above each structure.

absolute necessity for tumour progression/metastasis, there is clear morphological evidence for involvement of EMT in the process (169). By following 'genetically tagged' stromal and mammary epithelial cells, these authors concluded that stromal fibroblasts associated with MYC-induced tumours were of epithelial origin. Many of these cells had switched from cytokeratin and E-cadherin expression to vimentin and fibronectin. It is also reported that EMT markers are present in the tumour-host interface in colorectal cancers (170), but not in the bulk tumour providing strong evidence of EMT involvement in regulating invasiveness and tumour aggressiveness.
Cell adhesion molecules. A defining feature of EMT is the loss of the homotypic cell adhesion molecule E-cadherin and the occludins $(171,172)$ which together with other proteins such as the claudins and tight junction proteins are an integral component of epithelial cell adherens junctions that form the cohesive architecture of normal epithelia. Indeed, the loss of E-cadherin function is believed to play a pivotal role in the transition of breast tumours from a benign to an invasive state. Reduction of E-cadherin expression correlates with poor differentiation, invasiveness, aggressive metastatic behaviour, and an unfavourable prognosis (173-175). The importance of E-cadherin in the maintenance of normal tissue architecture and 
epithelial cell behaviour is reflected in the distinct mechanisms that converge to compromise its expression and function in breast cancer (171). Although inactivating mutations and the subsequent loss of heterozygosity at the E-cadherin CDH1 gene locus are important mechanisms for permanently silencing E-cadherin expression in many lobular breast cancers (175), EMT and metastatic progression are mostly associated with a reversible down-regulation of E-cadherin expression at the transcriptional level (176). This arises either through hypermethylation of the $\mathrm{CDH} 1$ promoter or transcriptional repression. Indeed, ductal breast cancers show heterogeneous loss of E-cadherin expression consistent with the notion that the tissue microenvironment at the invasive front may transiently down-regulate E-cadherin transcription (175). Consistent with the function of E-cadherin as a breast cancer invasion suppressor, experimental knockdown of E-cadherin is sufficient to confer metastatic ability (174). Conversely, exogenous E-cadherin inhibits the migration and extracellular matrix (ECM) invasion of metastatic breast cancer cells, although E-cadherin expression by itself is insufficient to completely reverse the mesenchymal phenotype (177-179). The consequences of E-cadherin loss for EMT are far reaching and reflect its dual roles in cell adhesion and signalling. First, E-cadherin loss causes the disassembly of inter-cellular adhesion complexes, thus loosening contacts between neighbouring epithelial cells and disrupting the overall tissue architecture. Second, the physical absence of E-cadherin serves to dissipate E-cadherin-mediated tethering of $\beta$-catenin to the cell membrane, thus permitting activation of WNT signalling (174). Furthermore, E-cadherin loss sets into motion multiple downstream transcriptional pathways leading to EMT and the induction of its own transcriptional repressors, SNAIL TWIST and ZEB1 (EF1), in a feed-forward loop that sustains E-cadherin repression and potentiates EMT (174).

Up-regulation of SNAIL, associated with reduced E-cadherin gene expression (180), is a consistent feature of high grade ductal carcinomas (181) and implicated in tumour recurrence (182). TWIST expression has been observed in breast tumour metastases and correlated with nodal involvement $(178,183)$. SNAIL2 likewise has been associated with disease aggressiveness in metastatic breast carcinoma (184). Loss of E-cadherin was also reported to be associated with the loss of cytokeratins CK8, 18 and 19 (179). Down-regulation of E-cadherin during EMT is often associated with a process known as 'cadherin switching' (185) which involves the induction of non-epithelial cadherins (e.g., N-cadherin and/or cadherin-11) $(171,179,186)$ typically found in mesenchymal cells. SNAIL, ZEB2/SIP1 and SNAIL2, can induce N-cadherin (and cadherin-11) expression during EMT, implicating it in the transcriptional re-programming of de-differentiating epithelial cells $(179,187,188)$. N-cadherin is highly expressed in invasive and metastatic human breast cancer cell lines and tumours and correlates with aggressive clinical behaviour. However, $\mathrm{N}$-cadherin ectopic expression also promotes motility, invasion and metastasis in E-cadherin-positive breast cancer cells (189) possibly in synergy with FGF2 (190) without impacting on their epithelial phenotype, suggesting that the malignant functions of $\mathrm{N}$-cadherin are dominant over E-cadherin and pointing to EMT-independent routes to metastasis. Interestingly, the association of cadherin switching, in ER-targeting shRNA transfected MCF-7 cells, with increased motility reflected by membrane ruffling and F-actin rearrangement suggests that the loss of cellular adhesion molecules following acquisition of endocrine resistance is a major factor influencing the cells to move and invade into the surrounding tissues (191). The general role of cadherins has been extensively reviewed by Berx and van Roy (192).

Besides E-cadherin loss, the integrity of adherens junctions may be compromised through down-regulation of the catenins, which are mainly localized within the normal epithelia as complexes contributing to inter-cellular adhesion by means of molecular bridges linking E-cadherin to the actin cytoskeleton. There is evidence for involvement of $\beta$-catenin-mediated gene transcription and establishment of EMT (193). EGFR modulation of $\beta$-catenin (tyrosine) phosphorylation was a feature of tamoxifen resistant breast cancer cells, accompanied by loss of association between $\beta$-catenin and E-cadherin, increased $\beta$-catenin and elevated transcription of its target genes implicated in tumour progression and EMT (194). Components of tight junctions and desmosomes such as claudins, occludins, desmogleins and desmocollins, as well as epithelial cell polarity genes, are co-ordinately down-regulated during different EMT programs, contributing to the disbanding of inter-cellular contacts and the loss of apicobasal polarity $(188,195)$.

Cytoskeletal proteins. Vimentin is a component of type III intermediate filaments and the archetypal mesenchymal marker most commonly used to categorize EMT (196) but it should be used in conjunction with other markers, as it has been noted that epithelial cell lines can also begin to express vimentin as part of the adaptation to in vitro culture conditions (197). Nevertheless, elevated vimentin expression correlates well with increased cell migration, invasion and EMT induction in several breast cancer cell lines $(198,199)$. It is co-ordinately regulated together with other mesenchymal markers, such as the ECM molecule tenascin C $(200,201)$, whose expression in human breast carcinomas correlates positively with overexpression of ERBB2 and down-regulation of ER. Although the mechanisms underlying E-cadherin down-regulation are fairly well documented, the molecular events triggering vimentin expression during EMT are less well delineated. That vimentin expression is a late event in EMT points to a temporal sequence of genetic events in which loss of epithelial features directly precedes and leads to up-regulation of mesenchymal genes (201). Direct activation of vimentin expression in human breast tumour cells (198) by $\beta$-catenin/T-cell factor/lymphocyte enhancer factor-1, is consistent with the activation of $\beta$-catenin as a downstream event ensuing from loss of E-cadherin. The indirect promotion of vimentin expression by ZEB2/SIP1 during EMT in a $\beta$-catenin-independent manner (202), suggests the existence of as yet unknown transactivators driving EMT associated vimentin expression.

The appearance of another mesenchymal marker, FSP1/ S100A4, is considered an important early event in the pathway leading to EMT, and its altered expression levels correlate with breast cancer progression. As a mesenchymal/EMT marker in a murine model of breast cancer FSP1/S100A4 has provided valuable in vivo evidence implicating EMT in the onset of metastasis (171) facilitated through the activation of matrix metalloproteinases (MMPs) such as MMP9 or SPARC (179). 
Matrix metalloproteinases. A family of more than 28 members, matrix metalloproteinases are up-regulated in nearly every tumour type and are intimately involved in cancer progression through cleavage and release of bioactive molecules that inhibit apoptosis and stimulate invasion, as well as through degradation of extracellular matrix (ECM) components that promote tumour cell growth. Cells treated with MMP-3 showed increased expression of the activated splice variant $\mathrm{RAClb}$, stimulating elevation of the levels of cellular reactive oxygen species, which in turn were responsible for increased expression of SNAIL and induction of EMT (203).

Lipocalin2 (Lcn2) is a member of a family of small extracellular proteins that play important roles in cell regulation, proliferation, and differentiation and is an MMP-9 associated protein. Yang et al (204) observed that LCN2 was overexpressed in human breast cancer cells and found to up-regulate mesenchymal markers, including vimentin and fibronectin, down-regulate E-cadherin, and significantly increase cell motility and invasiveness in previously non-invasive MCF-7 cells. They found that siRNA-mediated LCN2 silencing in aggressive breast cancer cells inhibited cell migration and development of the mesenchymal phenotype. Reduced expression of ER $\alpha$ and increased expression of the key EMT transcription factor SNAIL2, were observed with LCN2 expression. Over-expression of ER $\alpha$ in LCN-2 expressing cells reversed the EMT and reduced SNAIL2 expression, suggesting that $\mathrm{ER} \alpha$ negatively regulates LCN2-induced EMT.

Transcription factors. Kruppel-like factor 8 (KLF8) was initially identified as a transcriptional repressor of kruppel-like $\mathrm{C} 2 \mathrm{H} 2$ zinc-finger transcription factor family proteins. It was reported as a potent inducer of EMT and epithelial cell invasion, and a novel repressor of E-cadherin in epithelial cells (205). Its up-regulation is associated with the loss of E-cadherin expression in breast carcinoma cells and their consequent invasiveness. Their data showed that KLF8 was up-regulated in 50\% of E-cadherin-ve metastatic breast tumours, promoting cell motility, possibly by a mechanism secondary to its repression of E-cadherin. Alternatively, its effect may be due to direct regulation of other proteins that are critical to cell migration.

The ZEB family of zinc finger transcription factors have established functions in normal embryonic development. Recently, their association with EMT has led to investigations on their potential role in malignancy. ZEB1 up-regulation correlates closely with epithelial de-differentiation in both invasive ductal and undifferentiated lobular breast tumours. E-cadherin and other epithelial differentiation markers could be re-expressed by the induced down-regulation of $\delta \mathrm{EF} 1 /$ ZEB1 (downstream of SNAIL expression) (206) in breast cancer cell lines (207-209). Intriguingly, ZEB1 is also highly expressed in tumour-associated stromal cells, and there is speculation as to whether these mesenchymal cells are derived from tumour cells undergoing ZEB1-directed EMT (195). ZEB1 and ZEB2 bind to the E-box elements in the E-cadherin promoter causing transcriptional repression and EMT activation $(197,198)$.

Several interconnected signal transduction pathways and a number of extracellular signalling molecules have been implicated in the regulation of EMT-like processes during breast cancer progression $(210,211)$. Thus, EMT can be induced in breast cancer cell lines in vitro by extraneously added cytokines [e.g., tumour necrosis factor- $\alpha$ (TNF- $\alpha$ )] and growth factors (e.g., TGF- $\beta$, PDGF, HGF and FGF) through their respective cell surface receptors, leading to the activation of intracellular effectors such as RAS and other small GTPases, SRC, NF-kB, SMADs, $\beta$-catenin and integrins. EMT can also be induced by alterations in components of the ECM and in response to ECM remodelling by secreted MMPs $(210,211)$. All these instances highlight the importance of the tumour microenvironment in initiating EMT.

Intracellularly, the pathways include the basic helix-loophelix transcription factor TWIST, SNAIL1 and SNAIL2, the zinc-finger homeobox repressors ZEB1 and ZEB2/SIP1, GOOSECOID, and FOXC2. The activities of these EMT inducing transcription factors mostly converge in the transcriptional repression of E-cadherin, culminating in the suppression of the epithelial phenotype with concomitant upregulation of mesenchymal traits $(210,211)$.

Many studies have demonstrated the upregulation of EMT-inducing transcription factors during breast cancer progression and accorded their prognostic significance $(172,178,210)$. High levels of TWIST expression are associated with invasive lobular carcinomas (178), which originate from the epithelial cells of the milk-secreting lobular alveoli. EGF was reported to reduce E-cadherin expression and increase mesenchymal markers such as TWIST. Forced expression of EGFR in deficient cells reactivates TWIST expression but is suppressed by EGFR and Janus-activated kinase (JAK)/signal transducer and activator of transcription 3 (STAT3) inhibitors. TWIST expression is not significantly inhibited by kinases and signal transducers that target PI3K and MEK/ERK. Furthermore, TWIST promoter is significantly activated by constitutively active STAT3 but is suppressed by the JAK/ STAT3 inhibitor and dominant-negative STAT3. A 26-bp promoter region that contains putative STAT3 elements was also found to be required for the EGF-responsiveness of the TWIST promoter. Chromatin immunoprecipitation assays showed that TWIST promoter binding to the nuclear STAT3 is induced by EGF. An immunohistochemical study of 130 primary breast carcinomas showed parallel associations between non-nuclear EGFR and TWIST and between phosphorylated STAT3 and TWIST $(212,213)$.

GOOSECOID is another EMT-inducing transcription factor whose expression is significantly associated with ductal type breast tumours (214). It is known to initiate cell migration from the vertebrate Spemann organiser and its ectopic expression in breast cancer cells can lead to invasion associated events; down-regulation of E-cadherin, $\alpha$-catenin and $\gamma$-catenin proteins, concordant with the apparent loss of adherens junctions, up-regulation of $\mathrm{N}$-cadherin and vimentin, scattered distribution in culture, spindle-like morphology and increased cellular motility $(214,215)$. TWIST and GOOSECOID induce FOXC2, a transcription factor of the FOX family of forkhead helixturn-helix DNA binding proteins involved in EMT and organ development in many tissues (216). FOXC2 expression is associated with highly aggressive basal-like breast cancers (217) and interestingly, could induce mesenchymal gene transcription independently of E-cadherin repression.

Over-expression of SNAIL correlates with advanced tumour grade, lymph node metastasis, and poor clinical outcome in 
infiltrating ductal breast carcinomas (181). Significantly, in one of the first demonstrations of tumour related EMT in vivo, spontaneous up-regulation of SNAIL was associated with the recurrence of tumours with EMT characteristics in a reversible ERBB2-induced mouse breast cancer model (182). Loss of ER reduces MTA3 mediated inhibition of SNAIL hence promoting EMT (191). However, like SNAIL, the expression of SNAIL2 has been associated with poor clinical outcome in breast tumours (183). Indeed SNAIL2 has been implicated in the formation of tubular structures believed to represent a collective mode of migration at the invasive front of ductal breast carcinomas (218).

The re-expression of embryonic transcription factors during breast cancer progression may arise as a result of accumulating genetic instabilities or through reciprocal interactions with the local tissue microenvironment. In support of the former, loss of SINGLEMINDED-2s in the mouse mammary gland induces SNAIL2-mediated EMT, indicating how gene inactivation may circumvent EMT dormancy in the adult mammary gland (219). In support of the latter, there is evidence for the heterogeneous expression and nuclear translocation of SNAIL (220) and SNAIL2 (221) following exposure to hypoxia at the invasive front, highlighting the importance of the microenvironment in providing extracellular signals for initiation of EMT at metastasis.

Tumour progression and metastasis is promoted by the stabilization of the hypoxia-inducible factor- $1 \alpha$ (HIF-1 $\alpha)$ transcription complex caused by intra-tumoural hypoxia and ultimately causing treatment failure and mortality in several human cancers. TWIST was shown to be associated with HIF-1 $\alpha$ in inducing EMT and tumour metastasis by hypoxia or over-expression of HIF-1 $\alpha$ (222). TWIST expression was found to be regulated by HIF-1 binding to the hypoxiaresponse element (HRE) in the TWIST proximal promoter. Furthermore,TWIST deficient mice showed similar phenotypes to HIF-1 $\alpha$ null mice. However, EMT reversal was achieved by siRNA-mediated repression of TWIST in HIF-1 $\alpha$-overexpressing or hypoxic cells. Patients co-expressing HIF-1 $\alpha$, TWIST and SNAIL in primary head and neck tumours had the worst prognosis, caused by increased tumour metastasis providing evidence of a key signalling pathway involving HIF-1 $\alpha$ and TWIST that promotes EMT and tumour metastasis in response to intra-tumoural hypoxia (222).

Tyrosine kinase receptors. AXL is a member of the TAM (Tyro-Axl-Mer) receptor tyrosine kinases (RTK) that are known to have diverse effects on regulating cellular responses that include cell proliferation, cell survival, migration, autophagy, angiogenesis, natural killer cell differentiation and platelet aggregation (223). AXL shares the vitamin K-dependent ligand growth arrest-specific 6 . On the basis of its expression in many embryonic tissues it is thought to be involved in mesenchymal and neural development, with a restricted expression in smooth muscle cells in adult tissues (224). AXL was reported to be associated with EMT and its activation is linked to many signal transduction pathways, including AKT, MAPK, NF- $\kappa$ B, STAT, and others (225). AXL was originally identified as a transforming gene from a patient with chronic myelogenous leukemia, and since then it has been correlated with various high-grade cancers associated with poor prognosis
(223). It was shown that the presence of AXL is important for the growth of breast carcinoma and glioma cell xenografts $(226,227)$. It was also reported that the sole expression of AXL in breast cancer predicts poor overall patient survival. Furthermore, maintaining breast cancer invasiveness, growth in foreign microenviroments, and metastatic spread requires elevated AXL levels. All of these studies indicate that AXL is a unique EMT effector that is essential for breast cancer progression (186). Endocrine-resistant breast cancer cells show highly elevated expression of AXL (191).

Tumour suppressor genes. The Rb protein is mutated or expressed at low levels in breast carcinomas suggesting that a relationship may exist between loss or reduction of $\mathrm{Rb}$ function and a less-differentiated state, increased proliferation, and high metastatic potential. siRNA mediated knockdown of $\mathrm{Rb}$ in MCF-7 cells (228) disrupted inter-cellular adhesion and induced a mesenchymal-like phenotype. In addition, Rb depletion resulted in reduced expression of E-cadherin.

$\mathrm{p} 21^{\mathrm{CIP} 1 / \mathrm{WAF} 1}$ is a downstream effector of several tumour suppressors and also behaves as a cyclin-dependent kinase inhibitor of cell proliferation. It is also associated with EMT. Although its involvement in regulating features of tumour stem cells in vivo is unclear, deletion of p21CIP1, which enhanced the rate of tumourigenesis induced by mammarytargeted H-RAS or c-MYC, enhanced immunohistochemical features of EMT. Silencing of $\mathrm{p} 21^{\mathrm{CIP} 1}$ also enhanced features of EMT in transformed immortal human MEC lines. p21 $1^{\mathrm{CIP} 1}$ attenuated oncogene-induced BT-IC and mammosphere formation, suggesting a link between loss of $\mathrm{p} 21^{\mathrm{CIP} 1}$ and acquisition of breast cancer EMT and stem cell properties in vivo (229).

The homeobox genes. HOX genes, members of the homeobox gene family, are also believed to be associated with tumour progression. These are evolutionarily conserved genes encoding master transcription factors that play fundamental roles in regulating embryonic development and maintaining homeostasis through strictly regulated expression in various tissues and organs during adulthood. Several studies have described the association of HOX genes in the pathogenesis of multiple cancers; HOXA7 and HOXD13 in lung (230), HOXC4 and HOXC8 in prostate (231), HOXB7 in ovarian (232) and HOXA10 in endometrial cancer (233). It was reported that $60 \%$ of breast cancers had no HOXA5 expression (234). Furthermore, HOXA5 expression in MCF-7 cells caused p53-dependent apoptosis, whereas in HS578T cells expressing mutant p53, cell death was due to activation of the caspase pathway (235). HOXD10 was also reported to be extensively reduced as malignancy increases in epithelial cells. Restoring the expression of HOXD10 in MDA-MB-231 which is a highly invasive breast cancer cell line, could significantly reduce migration (236). In addition, increased MCF10A cell motility and invasion in vitro was associated with HOXB13 over-expression, while its ratio versus interleukin-17 $\beta$ receptor was predictive of tumour recurrence during adjuvant tamoxifen monotherapy (237). Microarray analysis of purified epithelial cells showed that HOXB7, which is involved in tissue remodeling of the normal mammary gland (238) was expressed in higher levels from normal epithelial cells to primary metastatic breast tumours to bone 


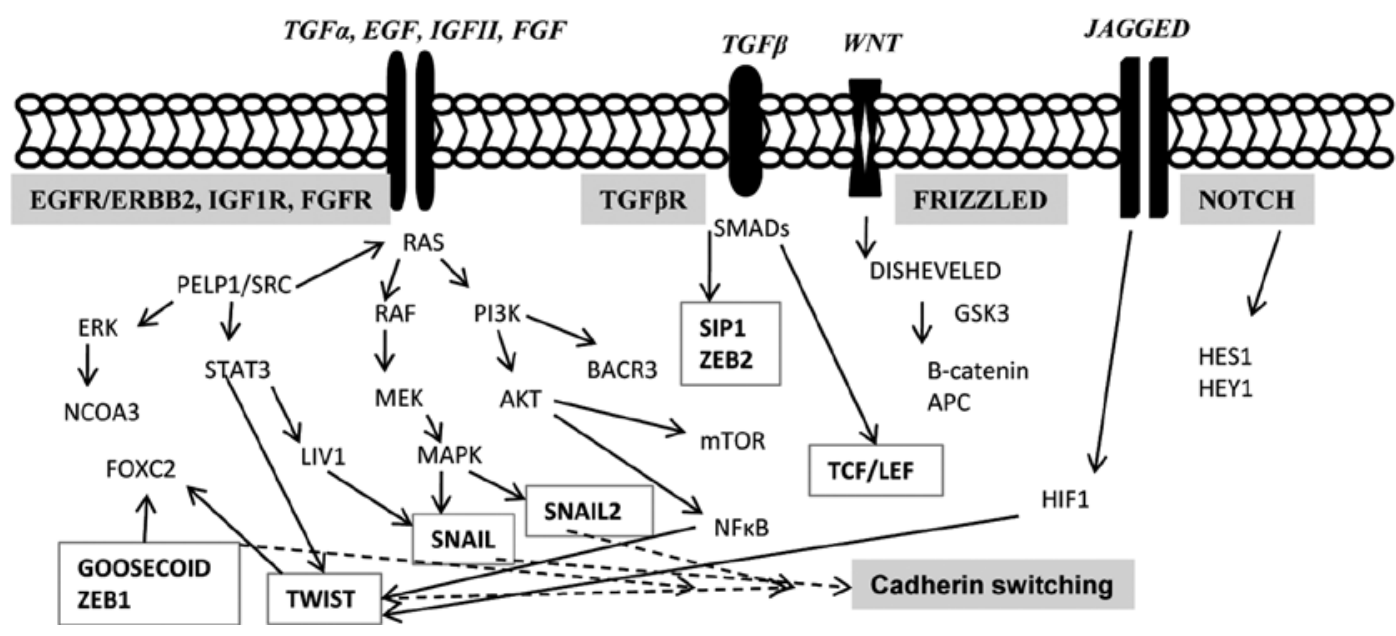

Figure 4. Signal transduction pathways implicated in EMT, showing some of the inter-relationships that are described and referenced in the text. Ligand stimulation of a variety of membrane receptors leads through intermediary molecules to activation of a set of nuclear transcription factors that regulate expression of epithelial/mesenchymal associated genes shown in Fig. 3. Note that many of these molecules are also involved in endocrine resistance. The so-called 'Master EMT regulators' are boxed.

metastatic lesions and is associated with development of breast cancer $(239,240)$. HOXB7 was located to a novel amplicon at 17q21.3, by the use of cDNA-based comparative genomic hybridization. This amplification was associated with poor prognosis in a panel of 186 breast cancer cases (241). Furthermore, HOXB7 over-expression regulated the expression of several growth and angiogenic factors, including basic FGF, vascular endothelial growth factor (VEGF), interleukin 8, ANG1, ANG2, and MMP9 in SKBR3 breast cancer cells, leading to formation of vascularized tumours when grown as xenografts in nude mice $(239,240)$. HOXB9 has a similar effect leading to increased cell motility and acquisition of mesenchymal phenotypes (242). Another homeoprotein, SIX1, has been shown to stimulate mammary tumour progression and metastasis in mouse models, through induction of EMT $(243,244)$.

EMT and tumour microenvironment. Although the tissue microenvironment is initially hostile to the development of a tumour, as cancers evolve, they circumvent the cytotoxic signals emanating from the surrounding tissue and provoke an inflammatory response that recruits tumour-infiltrating immune cells to the host-tumour interface. The cross-talk and reciprocal interactions between the tumour, its surrounding stroma, and infiltrating immune cells in the form of secreted MMPs, ECM components, growth factors, and cytokines enable localized tissue remodelling to promote tumour cell motility, EMT and the initiation of metastasis. Consistent with this model, co-culture of breast tumour cells with macrophages greatly enhances their migration and invasion by inducing EMT through NF- $\kappa$ B-mediated SNAIL stabilization (245). Furthermore, interleukin-6 induces EMT and promotes the invasiveness of MCF-7 cells, with clear ramifications for breast cancer patients with elevated serum levels of this cytokine (246).

Fig. 4 summarises various aspects that have been discussed above to illustrate how the diverse signalling pathways, some of which are implicated in endocrine resistance, lead to accumulation of several key mediators of the EMT.

\section{EMT, CSCs and endocrine resistance}

In their model of tamoxifen resistance, Hiscox et al $(194,247)$ showed that $\beta$-catenin, regulated by an autocrine action of EGFR, could act as both a mediator of E-cadherin dysfunction and a regulator of gene expression and promote development and progression of EMT. Development of endocrine resistance was accompanied by a change in $\beta$-catenin phosphorylation, loss of function of adherens junctions and increased transcription of $\beta$-catenin target genes. Interestingly, increased EGFR expression has been demonstrated within the EMT microenvironment, and its activation via autocrine production of EGFR ligands such as TGF $\alpha$ and amphiregulin has been reported to facilitate the EMT process (248).

Modulation of EGFR activity using gefitinib established it as a key player in the development of an aggressive, EMT-like phenotype in acquired tamoxifen-resistant breast cancer cells (71).

It has been suggested that the acquisition of enhanced EGFR/ERBB2 pathway signalling in $\mathrm{ER}^{+}$breast cancer with tamoxifen resistance potentially results from selection of a more stem cell-like phenotype. Expression of EGFR is seen in stem cells of the normal mammary gland in mice and humans $(249,250)$ whilst ER is predominantly expressed in the more differentiated luminal cells (251-253). The EGFR pathway was activated in CSCs of ductal carcinoma in situ (DCIS) of the breast. There is emerging evidence for a role of the ERBB2 pathway in the function of CSCs. Expression of ERBB2 and presence of $\mathrm{ALDH}^{+} \mathrm{CSCs}$ was positively correlated in one series of 491 breast cancer patients (254). The CSC populations of four ERBB2 ${ }^{+}$breast cancer cell lines have been demonstrated to express more ERBB2 mRNA and protein compared with the non-CSC population, regulated at the level of transcription. Furthermore, trastuzumab reduced mammosphere-forming 
capability and tumourigenicity on serial xenotransplantation (255). In a clinical study in ERBB2 over-expressing large primary breast cancers, lapatinib reduced the $\mathrm{CD} 44^{+} / \mathrm{CD} 24$ CSC fraction and mammosphere forming efficiency of the residual tumour, although not statistically significant (256). Notably treatment with chemotherapy alone increased the proportion of CSCs in the residual breast cancer $(256,257)$. So it seems plausible that up-regulation of the EGFR/ERBB2 pathway in endocrine-resistant breast cancer could indirectly reflect an enrichment of a CSC phenotype (258). The $\gamma$ secretase inhibitor DAPT or a NOTCH 4 neutralizing antibody significantly reduced mammosphere formation in primary human DCIS.

Antagonism of the NOTCH pathway causes amelioration of the effect of trastuzumab that reduces mammosphere formation in ERBB2 over-expressing cell lines (255). A 2-6-fold increase in NOTCH 1 activity induced nuclear accumulation of NOTCH 1 intracellular domain, and increased expression of NOTCH down-stream targets including HES and HEY 1 was seen in MCF-7, BT474 and SKBr3 cell lines after treatment with trastuzumab or lapatinib (259). Inhibition of the NOTCH pathway led to re-sensitisation to trastuzumab and the combination of NOTCH antagonism and trastuzumab inhibited growth in both trastuzumab sensitive and resistant cell lines (259).

Borley et al (260) reported that the antiestrogens tamoxifen and fulvestrant can promote an invasive phenotype in E-cadherin deficient $\mathrm{ER}^{+}$breast cancer cells through activation of SRC. However, estrogen deprivation mimicking the action of aromatase inhibitors did not promote invasiveness in the same cells. This means that acquired anti-estrogen resistance induced breast cancer cell invasion in the absence of E-cadherin but not necessarily EMT behaviour. An immunohistochemical profiling of SRC expression and signalling through EGFR showed simultaneous activation of GRB2/RAS/MAPK pathway, phospholipid metabolism involving PLD, PLC $\gamma$, and P13K and activation of the cytosolic SRC family kinases, ultimately promoting EMT-like events. SRC kinase was shown to modulate EMT-like characteristics in acquired endocrine resistance. src activation assayed in breast cancer biopsies showed a correlation with presence of distant metastasis, and shortened survival with tamoxifen therapy in $\mathrm{ER}^{+}$patients. Significantly, targeted inhibition of SRC kinase activity in tamoxifen-resistant breast cancer cells is accompanied by an efficient reduction in their invasive and migratory behaviour and even causing its reversion (MET) (247). In vitro studies suggest a role for c-MET signalling as a promoter of tumour progression and metastasis in vivo. $\mathrm{HGF} /$ scatter factor mediated activation of c-MET RTK induced 'cell scattering', a process fundamental to EMT. Analysis of ER- Faslodex-resistant MCF-7 cells showed significantly elevated levels of the HGF/ scatter factor receptor gene, c-MET. In addition, high levels of c-MET in breast tumours correlated with a significantly reduced survival rate $(261)$.

Mani et al (262) demonstrated for the first time that in addition to endowing cells with migratory and invasive potential, passage through EMT confers properties of breast CSCs. In breast tumours, the CD $44^{+} / \mathrm{CD} 24^{-} /$low antigenic phenotype defines a subpopulation of breast cancer cells enriched with cells with stem cell-like qualities, namely the ability to self-renew and reconstitute differentiated tumours (263). Thus, immortalized human mammary epithelial cells exposed to a range of different EMT-inducing stimuli (ectopic expression of SNAIL or TWIST or TGF- $\beta$ treatment), acquire the ability to self-renew and express the $\mathrm{CD} 44^{+/} \mathrm{CD} 24-/ \mathrm{low}$ antigenic phenotype. Conversely, CSC isolated from human breast cancer tissues express high levels of mRNAs encoding mesenchymal markers (262). Similarly, Morel et al (264) have shown that aberrant activation of the RAS/MAPK pathway generates a population of $\mathrm{CD} 44^{+} / \mathrm{CD} 24 \%$ low cells displaying combined EMT and stem cell attributes. Moreover, hypoxiainduced SNAIL2 expression is associated with the acquisition of a basal-like breast cancer phenotype and high levels of the stem cell regulatory genes CD133 and BMI1 (221). More recently, in vivo EMT induction by infiltrating CD8 T-cells has been shown to generate mesenchymal tumour cells with CSC properties (265), highlighting once again the paradoxical role of inflammation in exacerbating breast cancer progression. Furthermore, genome-wide transcriptional profiling has shown that metaplastic breast cancers and claudin-low tumours frequently exhibit EMT and stem cell-like features, likely contributing to their poor outcomes (168).

Collectively, these findings demonstrate that induction of EMT in differentiated breast epithelial tumour cells is sufficient to generate a sub-population of cancer cells with stem cell characteristics and the propensity to metastasize. Thus, EMT is not only important for cells to escape from the immediate vicinity of the tumour, but may also sustain primary tumour growth as well as promote the initiation and establishment of secondary tumours. The molecular pathways linking stem cell-like characteristics with EMT remain largely undefined. In a recently described mouse model of breast cancer metastasis to the lung, inhibition of WNT signalling through LRP6 was found to reduce stem cell-like properties and cause EMT reversal, restoration of the epithelial phenotype, and suppression of SNAIL2 and TWIST expression (266). Several components of the WNT signalling pathway have thus been implicated in mediating breast cancer metastasis from the orthotopic site to the lungs, suggesting that pharmacologic agents targeting the WNT pathway may be useful in controlling EMT-mediated breast cancer recurrence and metastasis (171).

Recent work by Weinberg's group (262) has linked the mesenchymal cell phenotype to stem cells in normal tissue and to CSCs. Immortalised human mammary epithelial cells (HMECs) induced to undergo EMT exhibited stem cell markers and had increased capacity to form mammospheres enriched in stem cells. Similarly stem cells isolated from normal and cancerous human and mouse mammary glands demonstrated markers of mesenchymal phenotype normally apparent in EMT. This included up-regulation of SNAIL and SNAIL2 and also the TGF $\beta$ signalling pathway which has been previously implicated in stem cell function (253).

Interestingly, recent analysis of a panel of breast cancer cell lines of luminal, intermediate and basal phenotypes has shown a significantly increased fraction of CSCs (defined by $\mathrm{CD}_{4} 4^{+} / \mathrm{CD} 2410 / \mathrm{ESA}^{+}$expression) in basal type breast cancers compared to hormone-sensitive luminal cancers (291). Furthermore, a positive correlation was shown between CSC number and cell line tumourigenicity in in vivo models (267). 
As ER negatively regulates the expression of the key transcription factors regulating EMT such as SNAIL and SNAIL2 $(268,269)$ a functionally redundant ER in endocrineresistant breast cancer might therefore promote a more mesenchymal stem-cell-like phenotype. In an MCF-7 model, tamoxifen resistant cells showed enhanced mammosphere forming capacity compared to tamoxifen sensitive cells, suggesting an increased CSC fraction (121).

Interestingly, EMT was implicated in the progression to distant metastatic disease and therapeutic resistance. It was shown that following adriamycin treatment of MCF-7 cells, TWIST 1 expression is induced and only cells undergoing adriamycin-induced EMT display enhanced invasion and multidrug resistance. TWIST 1 depletion by RNA interference blocked mesenchymal transformation, partially reversed multidrug resistance, and abolished invasion induced by adriamycin (270). Furthermore, TWIST1 RNA interference may show efficacy in adriamycin-based chemotherapies for breast cancer (271). Resistance to ERBB2 targeted therapy is a clinical problem that may undermine the success of ERBB2 targeted therapies such as trastuzumab and lapatinib. The ERBB2 pathway may play an important role in the maintenance of breast CSCs, induction of which, during EMT, may be the basis of resistance in ERBB2 targeted therapy (272). More generally, breast cancer cells may acquire resistance to conventional and targeted therapies upon conversion to a mesenchymal-like phenotype. A recent screen using transformed human breast cells that were experimentally transformed into mesenchymal cells showed that these cells which exhibit CSC properties, are more resistant to conventional chemotherapeutic drugs such as paclitaxel or doxorubicin (273).

Our group has established an endocrine-resistant cell line (termed pII) by transfection of MCF-7 cells with an shRNA targeting the ER $(274,275)$. These cells have constitutively down-regulated ER, exhibit a higher proliferative rate, increased aggressive behaviour reflected by accelerated motility and ability to penetrate into simulated extracellular matrix components, co-incident with a change from an epithelial morphology to a more mesenchymal one $(191,276)$. Rearrangement in these cells of the $\alpha$-actin cytoskeleton reflects increased appearance of lamellipodia and microspikes, features known to drive cellular motility (277). The morphological changes are accompanied by loss of E-cadherin and catenin and other epithelial markers such as keratins 18 and 19 and the gain of expression of mesenchymal markers such as $\mathrm{N}$-cadherin, tenascin $\mathrm{C}$ and fibronectin, PLAU, VEGF, CD68 and vimentin, characteristics shared with the MDAMB231 ER - cell line and hallmark features of cells undergoing EMT (171). Genome-wide microarray analysis confirmed a shift towards higher expression of genes involved in cell motility and interaction with the ECM as well as those characterising basal-like metaplastic and claudin-low tumour types reported to increase cell survival, stem cell-like properties, migratory and invasive capacity, thus promoting metastasis. Transcriptional repressors of E-cadherin that include ZEB1, ZEB2/SIP1 and SNAIL2 (174) were also elevated. Another significant group that is elevated in these cells are included in the ' 24 gene signature' of genes proposed as predictive of invasiveness (278): integrin, TIMP-2 and TIMP-3, MT1-MMP, PAI-1, Osteonectin/SPARC, thrombospondin-1, collagen (VI) $\alpha 1$ and collagen (I) $\alpha 2$. A further interesting feature is the ability of various tyrosine kinase inhibitors to block proliferation, motility and invasion in these cells (191) reflecting an important role of peptide growth factor receptors, particularly EGFR. So far, all the experimental data are consistent with the view that in these cells that have acquired endocrine independence, there is an associated change that closely mimicks EMT.

\section{Reversal of EMT}

The process of EMT associated with tumour progression and invasion presents a dramatic phenotypic change in which well differentiated epithelial cells possessing extensive junctional networks and a distinct pattern of gene expression, apparently re-organise and acquire molecular and morphological characteristics of cells of a completely different embryonic lineage with its own unique features. As detailed in the preceding sections, this is a seemingly complex multidimensional process involving an extraordinarily large number of contributory molecules of diverse function from structural components to receptors to signalling molecules and transcription factors. Which of these are simply in vitro phenomena and which have physiological significance remains to be confirmed. However that may be, it is clear that EMT presents a challenge to existing notions of cell lineage and differentiation. Reversal of this transition would have not only obvious therapeutic implications but also shed light on cellular mechanisms controlling cell specificity and function. In this respect, it is interesting that whereas tumour cells can undergo EMT in response to the inductive signals produced by an inflammatory tumour microenvironment, their exposure to the non-inflammatory microenvironment of a distant metastatic site may trigger at least partial EMT reversal and MET, a necessary process for tumour re-population. Metastatic lesions usually exhibit typical epithelial characteristics even when derived from poorly differentiated primary tumours (211).

TGF- $\beta$ signalling pathway. As a key mediator of fibrosis and a facilitator of metastasis, the TGF- $\beta$ signalling pathway may be a good target for EMT reversal $(172,279)$. TGF- $\beta$ induces EMT by both SMAD-dependent and independent signalling events $(164,265,280,281)$. SMAD4 is frequently mutated in pancreatic and colorectal cancers and in a subset of juvenile polyposis syndrome patients who have inherited mutated alleles of SMAD4 (282).

In advanced disease, TGF- $\beta$ can stimulate invasion and metastasis of tumour that has become TGF- $\beta$ insensitive. Invasion and metastasis of tumour cells can be inhibited by ectopic expression of dominant negative TGF- $\beta$ receptors (283). Colon cancer patients with inactivating mutations in TGF- $\beta$ type II receptor have a lower metastatic potential and increased survival $(284,285)$. TGF- $\beta 1$ ligand activates a heteromeric receptor of two transmembrane serine/threonine kinases, type I and II receptors (T $\beta$ RI and T $\beta$ RII) (T $\beta$ RII transphosphorylates $\mathrm{T} \beta \mathrm{RI}$, activating its kinase function) to exert its signalling effects. Activated T $\beta$ RI phosphorylates the intracellular proteins SMAD 2 and 3 which then associate with SMAD 4, translocating to the nucleus where the complex interacts with other transcriptional co-activators and co-repressors to regulate expression of numerous genes (174). This type of signalling 
that depends on SMAD up-regulates the expression of many transcription factors such as SNAIL, SNAIL2, TWIST, and members of the ZFH family, ZEB1 and ZEB2 $(178,179,188)$. Many other signalling proteins have also been implicated in the induction of EMT by TGF- $\beta 1$. These include RAS/MAPK (286), integrin $\beta-1$ (181), integrin-linked kinase (214), p38 mitogen-activated protein kinase (p38 MAPK) (217), RHOA kinase (ROCK) (182), PI3K (183), JAGGED1/NOTCH (218), SARA (219), NF-кB (220), PAR 6 (175,221) and ERK (245). The inhibition of T $\beta R I$ kinase and ROCK resulted in full reversal of the metastatic phenotype and gene expression patterns associated with EMT. This is caused by the mesenchymal gene expression blockade caused by T $\beta$ RI kinase which is mediated by down-regulating ZEB1 and ZEB2, while the epithelial structure is maintained by the ROCK inhibitor (281).

Another mechanism of EMT reversal involves expression of GATA3, a transcription factor regulating $\mathrm{T}$ lymphocyte differentiation and maturation. It is absent from metastatic lesions but expressed in early stage well differentiated breast cancers. A cuboidal-like epithelial phenotype and reduced cell invasive activity associated with increased E-cadherin expression and decreased N-cadherin, vimentin, and MMP-9 was mediated by ectopic expression of GATA3 in MDA-MB-231 cells that grew as non-metastatic smaller primary tumours. Control cells grew as larger metastatic tumours in xenografted mice. E-cadherin expression was induced by the binding of GATAlike motifs located in the E-cadherin promoter. MCF-7 cell fibroblastic transformation and increased invasion and metastasis resulted from siRNA induced GATA3 knockdown. Several studies on human breast cancers showed that GATA3 expression was correlated with elevated E-cadherin levels, ER expression, and longer disease-free survival indicating that GATA3 may drive invasive breast cancer cells to undergo EMT reversal which would ultimately lead to the suppression of cancer metastasis and invasion (213).

$u P A$. Urokinase-type plasminogen activator (uPA) and plasminogen activator inhibitor type I (PAI-1) system also have an important role in tumour invasion and metastasis (287-289) interacting with the matrix metalloproteinases system. Both molecules are well established as prognostic indicators of equal or greater utility than ER (290) and are also useful predictors of distant metastases in a subset of early, node-negative breast cancer patients (291). Hypoxia can promote EMT by inducing uPAR-dependent cell-signalling in cancer cells. MDA-MB 468 cells cultured in $1 \% \mathrm{O}_{2}$ exhibited increased UPAR expression, disruption of inter-cellular junctions, increased vimentin expression and loss of E-cadherin, indicating EMT (292). This effect could be reversed by shifting the cells to $21 \% \mathrm{O}_{2}$. EMT could also be reversed by silencing expression of endogenously-produced uPA, or by targeting uPAR-activated cell-signalling factors such as PI3K, SRC family kinases and extracellular signal-regulated kinase. MDA-MB 231 cells express high levels of UPA and UPAR and have a characteristic mesenchymal morphology under normoxic conditions $(21 \%$ $\mathrm{O}_{2}$ ). Silencing of uPA in these cells leads to decreased expression of vimentin and SNAIL, and induces a morphology characteristic of epithelial cells. Thus uPAR-initiated cell-signaling represents a potential target for EMT reversal in cancer cells. EMT reversal has also been observed during re-programmed gene expression in the mouse embryo induced by mutations in the TCF8 gene which leads to developmental defects caused by a reduction in progenitor cell proliferation and cell migration $(202,281)$.

\section{Concluding remarks}

There is considerable accumulated evidence which shows that the acquisition of resistance of breast cancers to endocrine therapies is accompanied by the gain of aggressive characteristics both in vivo and in vitro. EMT-like processes accompany acquisition of endocrine resistance by promoting a migratory phenotype that shows evidence of a switch from a network of cytokeratin intermediate filaments to one based upon vimentin. Underlying these events are complex signalling cascades which may be activated by numerous cytokines/growth factors. So, the ability of anti-growth factors and kinase inhibitors to antagonise such events may ultimately be of significance in the treatment of cancer patients as a means to prevent or reduce tumour dissemination. The link between development of endocrine resistance and EMT offers new therapeutic targets and new insights into the mechanisms underlying both processes in breast cancer progression. It remains to be seen whether the pleithora of phenotypic changes are indeed reversible, as suggested by the apparent re-differentitation back into epithelial character of blood-borne metastasizing cells that re-enter distant tissues to form secondary neoplastic deposits. Our current studies are addressing the issue of whether the EMT that we observe to be a direct consequence of loss of ER function in cultured cells, can be reversed simply by permitting the re-expression of ER. The nuclear transcription factors that trigger the loss of E-cadherin and other epithelial components could be key molecular targets whose blockade could prevent EMT induction and possibly block endocrine resistance.

\section{Acknowledgements}

We gratefully acknowledge the Kuwait University Research Administration for providing continued financial support in the form of research grants YM0809, GM01/05 and GM01/01.

\section{References}

1. Jordan VC and Brodie AM: Development and evolution of therapies targeted to the estrogen receptor for the treatment and prevention of breast cancer. Steroids 72: 7-25, 2007.

2. Jaiyesimi IU, Buzdar AU, Decker DA and Hortobagyi GN: Use of tamoxifen for breast cancer: twenty-eight years later. J Clin Oncol 13: 513-529, 1995.

3. Howell A, Pippen J, Elledge RM, Mauriac L, Vergote I, et al: Fulvestrant versus anastrozole for the treatment of advanced breast carcinoma: a prospectively planned combined survival analysis of two multicenter trials. Cancer 104: 236-239, 2005.

4. Cheung KL: Endocrine therapy for breast cancer: an overview. Breast 16: 327-343, 2007.

5. Gronemeyer H: Transcription activation by estrogen and progesterone receptors. Annu Rev Genet 25: 89-123, 1991.

6. Osborne CK, Schiff R, Fuqua SA and Shou J: Estrogen receptor: current understanding of its activation and modulation. Clin Cancer Res 7: S4338-S4342, 2001.

7. McKenna NJ, Lanz Rb and O'Malley BW: Nuclear receptor co-regulators: cellular and molecular biology. Endocr Rev 20: 321-344, 1999.

8. Leo C and Chen JD: The SRC family of nuclear receptor coactivators. Gene 245: 1-11, 2000. 
9. Shiau AK, Barstad D, Loria PM, Cheng L, Kushner PJ, Agard DA and Greene GL: The structural basis of estrogen receptor/ co-activator recognition and the antagonism of this interaction by tamoxifen. Cell 95: 927-937, 1998.

10. Tzukerman MT, Esty A, Santiso-Mere D, Danielian P, Parker MG et al: Human estrogen receptor transactivational capacity is determined by both cellular and promoter context and mediated by two functionally distinct intramolecular regions. Mol Endocrinol 8: 21-30, 1994

11. McDonnel DP, Clemm DL, Hermann T, Goldman ME and Pike JW: Analysis of estrogen receptor function in vitro reveals three distinct classes of antiestrogens. Mol Endocrinol 9: 659-669, 1995

12. Chen JD and Evans RM: A transcriptional co-repressor that interacts with nuclear hormone receptors. Nature 377: 454-457, 1995

13. Horlein AJ, Naar AM, Heinzel T, Torchia J, Gloss B, et al: Ligand-independent repression by the thyroid hormone receptor mediated by a nuclear receptor co-repressor. Nature 377 : 397-404, 1995

14. Lavinsky RM, Jepsen K, Heinzel T, Torchia J, Mullen TM, et al: Diverse signaling pathways modulate nuclear receptor recruitment of N-CoR and SMRT complexes. Proc Natl Acad Sci USA 95: 2920-2925, 1998.

15. Schiff R, Massarweh S, Shou J and Osborne CK: Breast cancer endocrine resistance: how growth factor signaling and estrogen receptor co-regulators modulate response. Clin Cancer Res 9: S447-S454, 2003.

16. Frasor J, Danes JM, Komm B, Chang KCN, Lyttle CR and Katzenellenbogen BS: Profiling of estrogen up- and downregulated gene expression in human breast cancer cells: insights into gene networks and pathways underlying estrogenic control of proliferation and cell phenotype. Endocrinology 144: 4562-4574, 2003

17. Ray P, Ghosh SK, Zhang DH and Ray A: Repression of interleukin-6 gene expression by 17 beta-estradiol: inhibition of the DNA-binding activity of the transcription factors NF-IL6 and NF-kappa B by the estrogen receptor. FEBS Lett 409: 79-85, 1997.

18. Kushner PJ, Agard DA, Greene GL, Scanlan TS, Shiau AK Uht RM and Webb P: Estrogen receptor pathways to AP-1. J Steroid Biochem Mol Biol 74: 311-317, 2000

19. Safe S: Transcriptional activation of genes by 17 betaestradiol through estrogen receptor-Sp1 interactions. Vitam Horm 62 231-252, 2001

20. Migliaccio A, Di Domenico M, Castoria G, De Falco A Bontempo P, Nola E and Auricchio F: Tyrosine kinase/p21ras/ MAP-kinase pathway activation by estradiol-receptor complex in MCF-7 cells. EMBO J 15: 1292-1300, 1996.

21. Kahlert S, Nuedling S, van Eickels M, Vetter H, Meyer R and Grohe C: Estrogen receptor alpha rapidly activates the IGF-1 receptor pathway. J Biol Chem 275: 18447-18453, 2000.

22. Sun M, Paciga JE, Feldman RI, Yuan Z, Coppola D, Lu YY, Shelley SA, Nicosia SV and Cheng JQ: Phosphatidylinositol3-OH Kinase (PI3K)/AKT2, activated in breast cancer, regulates and is induced by estrogen receptor alpha (ERalpha) via interaction between ERalpha and PI3K. Cancer Res 61: 5985-5991, 2001.

23. Chung YL, Sheu ML, Yang SC, Lin CH and Yen SH: Resistance to tamoxifen-induced apoptosis is associated with direct interaction between Her2/neu and cell membrane estrogen receptor in breast cancer. Int J Cancer 97: 306-312, 2002.

24. Wong CW, McNally C, Nickbarg E, Komm BS and Cheskis BJ: Estrogen receptor-interacting protein that modulates its non-genimic activity-crosstalk with Src/Erk phosphorylation cascade. Proc Natl Acad Sci USA 99: 14783-14788, 2002.

25. Schiff R, Massarweh S, Shou J, Bharwani L, Mohsin SK and Osborne CK: Cross-talk between estrogen receptor and growth factor pathways as a molecular target for overcoming endocrine resistance. Clin Cancer Res 10: S331-S336, 2004.

26. Shou J, Massarweh S, Osborne CK, Wakeling AE, Ali S, Weiss H and Schiff R: Mechanisms of tamoxifen resistance: increased estrogen receptor-HER2/neu cross-talk in ER/HER2-positive breast cancer. J Natl Cancer Inst 96: 926-935, 2004.

27. Bunone G, Briand PA, Miksicek RJ and Picard D: Activation of the unliganded estrogen receptor by EGF involves the MAP kinase pathway and direct phosphorylation. EMBO J 15: 2174-2183, 1996.

28. Font de Mora $\mathbf{J}$ and Brown M: AIB1 is a conduit for kinasemediated growth factor signaling to the estrogen receptor. Mol Cell Biol 20: 5041-5047, 2000.
29. Campbell RA, Bhat-Nakshatri P, Patel NM, Constantinidou D, Ali S and Nakshatri H: Phosphatidylinositol 3-kinase/AKTmediated activation of estrogen receptor $\alpha$ : a new model for anti-estrogen resistance. J Biol Chem 276: 9817-9824, 2001

30. Normanno N, Di Maio M, De Maio E, De Luca A, De Matteis A, Giordano A and Perrone F: Mechanisms of endocrine resistance and novel therapeutic strategies in breast cancer. Endocr Relat Cancer 12: 721-747, 2005

31. Saeki T, Cristiano A, Lynch MJ, Brattain M, Kim N, Normanno N, Kenney N, Ciardiello F and Salomon DS: Regulation by estrogen through the 50-flanking region of the transforming growth factor alpha gene. Mol Endocrinol 5: 1955-1963, 1991.

32. Normanno N, Qi CF, Gullick WJ, Persico G, Yarden Y, et al: Expression of amphiregulin, cripto-1 and heregulin-a in human breast cancer cell lines. Int J Oncol 2: 903-911, 1993

33. Salomon DS, Brandt R, Ciardiello F and Normanno N: Epidermal growth factor-related peptides and their receptors in human malignancies. Crit Rev Oncol Hemat 19: 183-232, 1995.

34. Levin ER: Bidirectional signaling between the estrogen receptor and the epidermal growth factor receptor. Mol Endocrinol 17: 309-317, 2003.

35. Razandi M, Pedram A, Park ST and Levin ER: Proximal events in signaling by plasma membrane estrogen receptors. J Biol Chem 278: 2701-2712, 2003.

36. Johnston SR: Combinations of endocrine and biological agents present status of therapeutic and presurgical investigations. Clin Cancer Res 11: S889-S899, 2005.

37. Kato S, Endoh H, Masuhiro Y, Kitamoto T, Uchiyama S, et al: Activation of the estrogen receptor through phosphorylation by mitogenactivated protein kinase. Science 270: 1491-1494, 1995.

38. Joel PB, Smith J, Sturgill TW, Fisher TL, Blenis J and Lannigan DA: pp90rsk1 regulates estrogen receptor mediated transcription through phosphorylation of Ser-167. Mol Cell Biol 18: $1978-1984,1998$

39. Ali S and Coombes RC: Endocrine-responsive breast cancer and strategies for combating resistance. Nat Rev 2: 101-112, 2002

40. Osborne CK, Shou J, Massarweh S, and Schiff R: Crosstalk between estrogen receptor and growth factor receptor pathways as a cause for endocrine therapy resistance in breast cancer. Clin Cancer Res 11: S865-S870, 2005.

41. Zilli M, Grassadonia A, Tinari N, Giacobbe AD, Gildetti S, et al: Molecular mechanisms of endocrine resistance and their implication in the therapy of breast cancer. Biochim Biophys Acta 1795: 62-81, 2009.

42. Massarweh S, Osborne CK, Jiang S, Wakeling AE., Rimawi M, Syed KM, Hilsenbeck S and Schiff R: Mechanisms of tumor regression and resistance to estrogen deprivation and fulvestrant in a model of estrogen receptor-positive, HER-2/neu-positive breast cancer. Cancer Res 66: 8266-8273, 2006.

43. Speirs V, Parkes AT, Kerin MJ, Walton DS, Carleton PJ, Fox JN and Atkin SL: Co-expression of estrogen receptor $\alpha$ and $\beta$ : poor prognostic factors in human breast cancer? Cancer Res 59: 525-528, 1999.

44. Fox EM, Davis RJ and Shupnik MA: ERbeta in breast cancer onlooker, passive player, or active protector? Steroids 73: 1039-1051, 2008.

45. Hartman J, Anders Ström A and Gustafsson JA: Estrogen receptor beta in breast cancer-diagnostic and therapeutic implications. Steroids 74: 635-641, 2009.

46. Wu RC, Qin J, Hashimoto Y, Wong J, Xu J, Tsai SY, Tsai MJ and O'Malley BW: Regulation of src-3 (pCIP/ACTR/AIB-1/RAC-3/ TRAM-1) coactivator activity by I kappa B kinase. Mol Cell Biol 22: 3549-3561, 2002

47. Shang Y and Brown M: Molecular determinants for the tissue specificity of SERMs. Science 295: 2465-2468, 2002.

48. Anzick SL, Kononen J, Walker RL, Azorsa DO, Tanner MM, et al: AIB1, a steroid receptor coactivator amplified in breast and ovarian cancer. Science 277: 965-968, 1997.

49. Murphy LC, Simon SL, Parkes A, Leygue E, Dotzlaw H, et al: Altered expression of estrogen receptor coregulators during breast tumorigenesis. Cancer Res 60: 6266-7621, 2000.

50. List HJ, Reiter R, Singh B, Wellstein A and Riegel AT: Expression of the nuclear coactivator AIB1 in normal and malignant breast tissue. Breast Cancer Res Treat 68: 21-28, 2001

51. Xu J, Liao L, Ning G, Yoshida-Komiya H, Deng C and O'Malley BW: The steroid receptor coactivator src-3 (p/CIP/ RAC3/AIB1/ACTR/TRAM-1) is required for normal growth puberty, female reproductive function, and mammary gland development. Proc Natl Acad Sci USA 97: 6379-6384, 2000. 
52. List HJ, Lauritsen KJ, Reiter R, Powers C, Wellstein A and Riegel AT: Ribozyme targeting demonstrates that the nuclear receptor co-activator AIB1 is a rate-limiting factor for estrogendependent growth of human MCF-7 breast cancer cells. J Biol Chem 276: 23763-23768, 2001

53. Webb P, Nguyen P, Shinsako J, Anderson C, Feng W, et al: Estrogen receptor activation function 1 works by binding p160 co-activator proteins. Mol Endocrinol 12: 1605-1618, 1998.

54. Ring A and Dowsett M: Mechanisms of tamoxifen resistance. Endocr Relat Cancer 11: 643-658, 2004.

55. Osborne CK, Bardou V, Hopp TA, Chamness GC, Hilsenbeck SG, et al: Role of the estrogen receptor co-activator AIB1 (src-3) and HER-2/neu in tamoxifen resistance in breast cancer. J Natl Cancer Inst 95: 353-361, 2003.

56. Atanaskova N, Keshamouni VG, Krueger JS, Schwartz JA, Miller F and Reddy KB: MAP kinase/estrogen receptor crosstalk enhances estrogen-mediated signaling and tumor growth but does not confer tamoxifen resistance. Oncogene 21: 4000-4008, 2002.

57. Gururaj AE, Rayala SK, Vadlamudi RK and Kumar R: Novel mechanisms of resistance to endocrine therapy: genomic and nongenomic considerations. Clin Cancer Res 12: S1001-S1007, 2006 .

58. Johnston SR, Lu B, Scott GK, Kushner PJ, Smith IE, Dowsett M and Benz CC: Increased activator protein-1 DNA binding and c-jun NH2-terminal kinase activity in human breast tumors with acquired tamoxifen resistance. Clin Cancer Res 5: 251-256, 1999.

59. Schiff R, Reddy P, Ahotupa M, Coronado-Heinsohn E, Grim M and Hilsenbeck SG: Oxidative stress and AP-1 activity in tamoxifen-resistant breast tumour in vivo. J Natl Cancer Inst 29: 1926-1934, 2000.

60. Zhou Y, Yau C, Gray JW, Chew K, Dairkee SH, et al: Enhanced $\mathrm{NF} \kappa \mathrm{B}$ and $\mathrm{AP}-1$ transcriptional activity associated with antiestrogen resistant breast cancer. BMC Cancer 7: 59-64, 2007.

61. Dorssers LC, van Agthoven T, Dekker A, van Agthoven TL and Kok EM: Induction of antiestrogen resistance in human breast cancer cells by random insertional mutagenesis using defective retroviruses: identification of bcar-1, a common integration site. Mol Endocrinol 7: 870-878, 1993.

62. Van de Flier S, Brinkman A, Look MP, Kok EM, Meijer-van Gelder ME, Klijn JG, Dorssers LC and Foekens JA: Bcar1/ p130Cas protein and primary breast cancer: prognosis and response to tamoxifen treatment. J Natl Cancer Inst 92: 120-127, 2000.

63. Riggins RB, Schrecengost RS, Guerrero MS and Bouton AH: Pathways to tamoxifen resistance. Cancer Lett 256: 1-24, 2007.

64. Van Agthoven T, van Agthoven TL, Dekker A, van der Spek PJ, Vreede L and Dorssers LC: Identification of BCAR3 by a random search for genes involved in antiestrogen resistance of human breast cancer cells. EMBO J 17: 2799-2808, 1998.

65. Cai D, Iyer A, Felekkis KN, Near RI, Luo Z, et al: AND-34/ BCAR3, a GDP exchange factor whose over-expression confers antiestrogen resistance, activates Rac, PAK1, and the cyclin D1 promoter. Cancer Res 63: 6802-6808, 2003.

66. Smith CL, Nawaz Z and O'Malley BW: Coactivator and corepressor regulation of the agonist/antagonist activity of the mixed antiestrogen, 4-hydroxytamoxifen. Mol Endocrinol 11: 657-666, 1997.

67. Jackson TA, Richer JK, Bain DL, Takimoto GS, Tung L and Horwitz KB: The partial agonist activity of antagonist-occupied steroid receptors is controlled by a novel hinge domain-binding coactivator L7/SPA and the co-repressors N-CoR or SMRT. Mol Endocrinol 11: 693-705, 1997.

68. Szapary D, Huang Y and Stoney Simons S: Opposing effects of co-repressor and co-activators in determining the dose-response curve of agonists, and residual agonist activity of antagonists, for glucocorticoid receptor-regulated gene expression. Mol Endocrinol 13: 2108-2121, 1999.

69. Liu Z, Auboeuf D, Wong J, Chen JD, Tsai SY, Tsai MJ and O'Malley BW: Co-activator/co-repressor ratios modulate PR-mediated transcription by the selective receptor modulator RU486. Proc Natl Acad Sci USA 99: 7940-7944, 2002.

70. Moy B and Goss PE: Estrogen receptor pathway: resistance to endocrine therapy and new therapeutic approaches. Clin Cancer Res 12: 4790-4793, 2006

71. Nicholson RI, Hutcheson IR, Jones HE, Hiscox SE, Giles M, Taylor KM and Gee JMW: Growth factor signalling in endocrine and anti-growth factor resistant breast cancer. Rev Endocr Metab Disord 8: 241-253, 2007.
72. Nicholson RI, Staka C, Boyns F, Hutcheson IR and Gee JM: Growth factor-driven mechanisms associated with resistance to estrogen deprivation in breast cancer: new opportunities for therapy. Endocr Relat Cancer 11: 623-641, 2004.

73. Hiscox S, Gee J and Nicholson RI (eds): Therapeutic resistance to anti-hormonal drugs in breast cancer. In: New Molecular Aspects and Their Potential as Targets. Chapter 8. Springer Netherlands, pp139-147, 2009.

74. Martin MB, Garcia-Morales P, Stoica A, Solomon HB, Pierce M, et al: Effects of 12-O-tetradecanoilphorbol-13-acetate on estrogen receptor activity in MCF-7 cells. J Biol Chem 270: 25244-25251, 1995.

75. Stoica A, Saceda M, Fakhro A, Salomon HB, Fenster BD and Martin MB: The role of transforming growth factor-beta in regulation of estrogen receptor expression in the MCF-7 breast cancer cell line. Endocrinology 138: 1498-1505, 1997.

76. Stoica A, Saceda M, Doraiswamy VL, Coleman C and Martin MB: Regulation of estrogen receptor-alpha gene expression by epidermal growth factor. J Endocrinol 165: 371-378, 2000.

77. Stoica A, Saceda M, Fakhro A, Joyner M and Martin MB: Role of insulin-like growth factor-I in regulating estrogen receptoralpha gene expression. J Cell Biochem 76: 605-614, 2000.

78. Mueller H, Kueng W, Schoumacher F, Herzer S and Eppenberger U: Selective regulation of steroid receptor expression in MCF-7 breast cancer cells by a novel member of the heregulin family. Biochem Biophys Res Commun 217: 1271-1278, 1995.

79. Tang CK, Perez C, Grunt T, Waibel C, Cho C and Lupu R: Involvement of heregulin-beta2 in the acquisition of the hormoneindependent phenotype of breast cancer cells. Cancer Res 56: 3350-3358, 1996.

80. Liu Y, El-Ashry D, Chen D, Ding IY and Kern FG: MCF-7 breast cancer cells overexpressing transfected c-erbB-2 have an in vitro growth advantage in estrogen-depleted conditions and reduced estrogen dependence and tamoxifen-sensitivity in vivo. Breast Cancer Res Treat 34: 97-117, 1995.

81. Pietras RJ, Arboleda J, Reese DM, Wongvipat N, Pegram MD, et al: HER-2 tyrosine kinase pathway targets estrogen receptor and promotes hormone independent growth in human breast cancer cells. Oncogene 10: 2435-2446, 1995.

82. El-Ashry D, Miller DL, Kharbanda S, Lippman ME and Kern FG: Constitutive Raf-1 kinase activity in breast cancer cells induces both estrogen-independent growth and apoptosis. Oncogene 15: 423-435, 1997.

83. Oh AS, Lorant LA, Holloway JN, Miller DL, Kern FG and El-Ashry D: Hyperactivation of MAPK induces loss of ERalpha expression in breast cancer cells. Mol Endocrinol 15: 1344-1359, 2001.

84. Koga M, Musgrove EA and Sutherland RL: Modulation of the growth-inhibitory effects of progestins and the antiestrogen hydroxyclomiphene on human breast cancer cells by epidermal growth factor and insulin. Cancer Res 49: 112-116, 1989.

85. Piccart M, Lohrisch C, Di Leo A and Larsimont D: The predictive value of HER2 in breast cancer. Oncology 61: 73-82, 2001.

86. Britton D, Hutcheson IR, Barrow D, McClelland RA and Nicholson RI: Estrogen receptor phosphorylation in hormone sensitive and anti-hormone resistant breast cancer cells. Breast Cancer Res Treat 82: S61, 2003.

87. Hutcheson IR, Knowlden JM, Madden TA, Barrow D, Gee JM, Wakeling AE and Nicholson RI: Estrogen receptor-mediated modulation of the EGFR/MAPK pathway in tamoxifen-resistant MCF-7 cells. Breast Cancer Res Treat 81: 81-93, 2003.

88. Knowlden JM, Hutcheson IR, Jones HE, Madden T, Gee JM, et al: Elevated levels of epidermal growth factor receptor/c-erbB2 heterodimers mediate an autocrine growth regulatory pathway in tamoxifen resistant MCF-7 cells. Endocrinology 144: 1032-1044, 2003.

89. Jordan NJ, Gee JM, Barrow D, Wakeling AE and Nicholson RI: Increased constitutive activity of PKB/akt in tamoxifen resistant breast cancer MCF-7 cells. Breast Cancer Res Treat 87: 167-180, 2004.

90. Gee JM, Harper ME, Hutcheson IR, Madden TA, Barrow D, et al: The antiepidermal growth factor receptor agent gefitinib (ZD1839/ Iressa) improves antihormone response and prevents development of resistance in breast cancer in vitro. Endocrinology 144: 5105-5117, 2003

91. McClelland RA, Barrow D, Madden TA, Dutkowski CM, Pamment J, et al: Enhanced epidermal growth factor receptor signaling in MCF-7 breast cancer cells after long-term culture in the presence of the pure antiestrogen ICI 182780 (Faslodex). Endocrinology 142: 2776-2788, 2001. 
92. Gutierrez MC, Detre S, Johnston S, Mohsin SK, Shou J, et al: Molecular changes in tamoxifen-resistant breast cancer: relationship between estrogen receptor, HER-2, and p38 mitogen-activated protein kinase. J Clin Oncol 23: 2469-2476, 2005.

93. Robertson JFR, Gutteridge E, Cheung KL, Owers R, Koehler M, Hamilton L, Gee J and Nicholson RI: Gefitinib (ZD1839) is active in acquired tamoxifen (TAM)-resistant estrogen receptor (ER)-positive and ER-negative breast cancer: results from a phase II study. Proc ASCO 22: abs. 7, 2003.

94. Nicholson RI, Gee JMW, Barrow D, Pamment JS, Knowlden JM and McClelland R: Endocrine resistance in breast cancer can involve a switch towards EGFR signaling pathways and a gain of sensitivity to an EGFR-selective tyrosine kinase inhibitor, ZD1839. AACR-NCI-EORTC Int Conf Mol Targets Cancer Ther, 1999.

95. Hua G, Zhu B, Rosa F, Deblon N, Adélaïde J, Kahn-Perlès B, Birnbaum D and Imbert J: A negative feedback regulatory loop associates the tyrosine kinase receptor ERbB2 and the transcription factor GATA4 in breast cancer cells. Mol Cancer Res 7: 402-414, 2009.

96.Zuo T, Wang L, Morrison C, Chang X, Zhang H, Li W, Liu Y, Wang Y, et al: FOXP3 is an X-linked breast cancer suppressor gene and an important repressor of the HER-2/erbB2 oncogene. Cell 129: 1275-1286, 2007.

97. Hurtado A, Holmes KA, Geistlinger TR, Hutcheson A, et al: Regulation of eRbB2 by estrogen receptor-PAX2 determines response to tamoxifen. Nature 456: 663-666, 2008

98. Musgrove EA and Sutherland RL: Biological determinants of endocrine resistance in breast cancer. Nat Rev 9: 631-643, 2009.

99. Dowsett M, Harper-Wynne C, Boeddinghaus I, Salter J, Hills M, et al: HER-2 amplification impedes the anti-proliferative effects of hormone therapy in estrogen receptor positive primary breast cancer. Cancer Res 61: 8452-8458, 2001.

100. Ellis MJ, Coop A, Singh B, Mauriac L, Llombert-Cussac A, et al: Letrozole is more effective neoadjuvant endocrine therapy than tamoxifen for ErbB-1- and/or ErbB-2-positive, estrogen receptor-positive primary breast cancer: evidence from a phase III randomized trial. J Clin Oncol 19: 3808-3816, 2001.

101. Knowlden JM, Hutcheson IR, Barrow D and Nicholson RI IGF-1R and EGFR crosstalk in tamoxifen resistant breast cancer cells. Breast Cancer Res Treat 82: S171, 2003.

102. Nicholson RI, Hutcheson IR, Britton D, Knowlden JM, Jones HE et al: Growth factor signalling networks in breast cancer and resistance to endocrine agents: new therapeutic strategies. J Steroid Biochem Mol Biol 93: 257-262, 2005.

103. Arpino G, Wiechmann L, Osborne CK and Schiff R: Crosstalk between the estrogen receptor and the HER tyrosine kinase receptor family: molecular mechanism and clinical implications for endocrine therapy resistance. Endocr Rev 29: 217-233, 2008.

104. Miller TW, Pérez-Torres M, Narasanna A, Guix M, Stål O and Pérez-Tenorio $\mathrm{G}$, et al: Loss of phosphatase and tensin homologue deleted on chromosome 10 engages ErbB3 and insulin-like growth factor-I receptor signaling to promote antiestrogen resistance in breast cancer. Cancer Res 69: 4192-4201, 2009.

105. Datta S, Brunet A and Greenberg ME: Cellular survival: a play in three akts. Genes Dev 13: 2905-2927, 1999.

106. Clark AS, West K, Streicher S and Dennis PA: Constitutive and inducible akt activity promotes resistance to chemotherapy, trastuzumab, or tamoxifen in breast cancer cells. Mol Cancer Ther 1: 707-717, 2002.

107. Simoncini T, Hafezi-Moghadam A, Brazil DP, Ley K, Chin WW and Liao JK: Interaction of estrogen receptor with the regulatory subunit of phosphatidylinositol-3-OH kinase. Nature 407 538-541, 2000.

108. Angel P and Karin M: The role of jun, fos and AP-1 complex in cell proliferation and transformation. Biochim Biophys Acta 1072: 129-157, 1991.

109. Kyriakis JM, Banerjee P, Nikolakaki E, Dai T, Rubie EA Ahmad MF, Avruch J and Woodgett JR: The stress-activated protein kinase subfamily of c-jun kinases. Nature 369: 156-160, 1994.

110. Dumont JA, Bitonti AJ, Wallace CD, Baumann RJ, Cashman EA and Cross-Doersen DE: Progression of MCF-7 breast cancer cells to antiestrogen-resistant phenotype is accompanied by elevated levels of AP-1 DNA-binding activity. Cell Growth Differ 7: 351-359, 1996.
111. Clarke R, Skaar TC, Bouker KB, Davis N, Lee YR, Welch JN and Leonessa F: Molecular and pharmacological aspects of antiestrogen resistance. J Steroid Biochem Mol Biol 76: 71-84, 2001.

112. New L and Han J: The p38 MAP kinase pathway and its biological function. Trends Cardiovasc Med 8: 220-229, 1998.

113. Zhang CC and Shapiro DJ: Activation of the p38 mitogen-activated protein kinase pathway by estrogen or by 4-hydroxytamoxifen is coupled to estrogen receptor-induced apoptosis. J Biol Chem 75: 479-486, 2000.

114. Dowsett M, Gutierrez C, Moshin S, Schiff R, Detre S, Johnston SR and Osborne CK: Molecular changes in tamoxifen relapsed breast cancer: Relationship between ER, HER2 and P38-MAP-kinase. 39th Annual Meeting, Chicago, IL, USA. Proc ASCO 22: abs. 7, 2003.

115. Chang HL, Sugimoto Y, Liu S, Ye W, Wang LS, Huang YW and Lin YC: Keratinocyte growth factor (KGF) induces tamoxifen (Tam) resistance in human breast cancer MCF-7 cells. Anticancer Res 26: 1773-1784, 2006

116. Raouf A, Zhao Y, To K, Stingl J, Delaney A, Barbara M, Iscove $\mathrm{N}$, et al: Transcriptome analysis of the normal human mammary cell commitment and differentiation process. Cell Stem Cell 3: 109-118, 2008.

117. Farnie G, Clarke RB, Spence K, Pinnock N, Brennan K, Anderson NG and Bundred NJ: Novel cell culture technique for primary ductal carcinoma in situ: role of Notch and epidermal growth factor receptor signaling pathways. J Natl Cancer Inst 99: 616-627, 2007.

118. Dontu G, Jackson KW, McNicholas E, Kawamura MJ, Abdallah WM, Wicha MS, et al: Role of Notch signaling in cell-fate determination of human mammary stem/progenitor cells. Breast Cancer Res 6: R605-R615, 2004.

119. Stylianou S, Clarke RB and Brennan K: Aberrant activation of notch signalling in human breast cancer. Cancer Res 66: $1517-1525,2006$.

120. Rizzo P, Miao H, D'Souza G, Osipo C, Song LL, Yun J, et al: Cross-talk between notch and the estrogen receptor in breast cancer suggests novel therapeutic approaches. Cancer Res 68: 5226-5235, 2008.

121. O'Brien CS, Sacha JH, Farnie G and Clarke RB: Resistance to endocrine therapy: are breast cancer stem cells the culprits? J Mamm Gland Biol Neoplasia 14: 45-54, 2009.

122. Dowsett M, Smith IE, Ebbs SR, Dixon JM, Skene A, et al: Proliferation and apoptosis as markers of benefit in neoadjuvant endocrine therapy of breast cancer. Clin Cancer Res 12: S1024-S1030, 2006.

123. Doisneau-Sixou SF, Sergio CM, Carroll JS, Hui R, Musgrove EA and Sutherland RL: Estrogen and antiestrogen regulation of cell cycle progression in breast cancer cells. Endocr Relat Cancer 10: $179-186,2003$

124. Prall OWJ, Rogan EM, Musgrove EA, Watts CKW and Sutherland RL: c-Myc or cyclin D1 mimics estrogen effects on cyclin E-Cdk2 activation and cell cycle re-entry. Mol Cell Biol 18: 4499-4508, 1998.

125. Venditti M, Iwasiow B, Orr FW and Shiu RP: C-myc gene expression alone is sufficient to confer resistance to antiestrogen in human breast cancer cells. Int J Cancer 99: 35-42, 2002.

126. Hui R, Finney GL, Carroll JS, Lee CS, Musgrove EA and Sutherland RL: Constitutive over-expression of cyclin D1 but not cyclin E confers acute resistance to antiestrogens in T-47D breast cancer cells. Cancer Res 62: 6916-6923, 2002.

127. Dhillon NK and Mudryj M: Ectopic expression of cyclin E in estrogen responsive cells abrogates antiestrogen mediated growth arrest. Oncogene 21: 4626-4634, 2002

128. Cariou S, Donovan JC, Flanagan WM, Milic A, Bhattacharya N and Slingerland JM: Down-regulation of $\mathrm{p} 21^{\mathrm{WAF} 1 / \mathrm{CIP1}}$ or $\mathrm{p} 27^{\mathrm{Kip} 1}$ abrogates antiestrogen-mediated cell cycle arrest in human breast cancer cells. Proc Natl Acad Sci USA 97: 9042-9046, 2000.

129. Carroll JS, Prall OWJ, Musgrove EA and Sutherland RL: A pure estrogen antagonist inhibits cyclin E-Cdk2 activity in MCF-7 breast cancer cells and induces accumulation of p130-E2F4 complexes characteristic of quiescence. J Biol Chem 275: 38221-38229, 2000.

130. Bosco EE, Wang Y, Xu H, Zilfou JT, Knudsen KE, Aronow BJ, Lowe SW and Knudsen ES: The retinoblastoma tumor suppressor modifies the therapeutic response of breast cancer. J Clin Invest 117: 218-228, 2007.

131. Varma H, Skildum AJ and Conrad SE: Functional ablation of $\mathrm{pRb}$ activates $\mathrm{Cdk} 2$ and causes antiestrogen resistance in human breast cancer cells. PLoS One 2: e1256, 2007. 
132. Wang Y, Dean JL, Millar EK, Tran TH and McNeil CM: Cyclin $\mathrm{D} 1 \mathrm{~b}$ is aberrantly regulated in response to therapeutic challenge and promotes resistance to estrogen antagonists. Cancer Res 68 : $5628-5638,2008$

133. Mukherjee S and Conrad SE: c-Myc suppresses p21 $1^{\mathrm{WAF} 1 / \mathrm{CIP} 1}$ expression during estrogen signaling and antiestrogen resistance in human breast cancer cells. J Biol Chem 280: 17617-17625, 2005.

134. Alles CM, Gardiner-Garden M, Nott DJ, Wang Y, Foekens JA, et al: Metaanalysis and gene set enrichment relative to ER status reveal elevated activity of MYC and E2F in the 'basal' breast cancer subgroup. PLoS One 4: e4710, 2009.

135. Caldon CE, Sergio CM, Schütte J, Boersma MN, Sutherland RL, Carroll JS and Musgrove EA" Estrogen regulation of cyclin E2 requires cyclin D1, but not c-Myc. Mol Cell Biol 29: 4623-4639, 2009.

136. Coqueret O: Linking cyclins to transcriptional control. Gene 299: 35-55, 2002.

137. Ishii Y, Waxman S and Germain D: Tamoxifen stimulates the growth of cyclin D1-overexpressing breast cancer cells by promoting the activation of signal transducer and activator of transcription 3. Cancer Res 68: 852-860, 2008.

138. Butt AJ, McNeil CM, Musgrove EA and Sutherland RL: Downstream targets of growth factor and estrogen signalling and endocrine resistance: the potential roles of c-Myc, cyclin D1 and cyclin E. Endocr Relat Cancer 12: S47-S59, 2005.

139. Caldon CE, Daly RJ, Sutherland RL and Musgrove EA: Cell cycle control in breast cancer cells. J Cell Biochem 97: 261-274, 2006.

140. Chu IM, Hengst L and Slingerland JM: The Cdk inhibitor p27 in human cancer: prognostic potential and relevance to anticancer therapy. Nat Rev Cancer 8: 253-267, 2008.

141. Miller TE, Ghoshal K, Ramaswamy B, Roy S, Datta J, Shapiro CL, Jacob S and Majumder S: MicroRNA-221/222 confers tamoxifen resistance in breast cancer by targeting p $27^{\text {Kipl }}$ J Biol Chem 283: 29897-29903, 2008.

142. Zhao JJ, Lin J, Yang H, Kong W, He L, Ma X, Coppola D and Cheng JQ: MicroRNA-221/222 negatively regulates estrogen receptor $\alpha$ and is associated with tamoxifen resistance in breast cancer. J Biol Chem 283: 31079-31086, 2008.

143. Liu R, Wang L, Chen G, Katoh H, Chen C, Liu Y and Zheng P: FOXP3 up-regulates p21 expression by site-specific inhibition of histone deacetylase 2 /histone deacetylase 4 association to the locus. Cancer Res 69: 2252-2259, 2009.

144. Pérez-Tenorio G, Berglund F, Esguerra Merca A, Nordenskjöld B, Rutqvist LE, Skoog L and Stăl O: Cytoplasmic p21 $1^{\mathrm{WAF} / \mathrm{CIP}}$ correlates with Akt activation and poor response to tamoxifen in breast cancer. Int J Oncol 28: 1031-1042, 2006.

145. Iorns E, Turner NC, Elliott R, Syed N, Garrone O, et al: Identification of CDK10 as an important determinant of resistance to endocrine therapy for breast cancer. Cancer Cell 13: 91-104, 2008.

146. Riggins RB, Bouton AH, Liu MC and Clarke R: Antiestrogens, aromatase inhibitors, and apoptosis in breast cancer. Vitam Horm 71: 201-237, 2005.

147. Mandlekar S and Kong AN: Mechanisms of tamoxifen induced apoptosis. Apoptosis 6: 469-477, 2001.

148. Riggins, RB, Zwart A, Nehra R and Clarke R: The nuclear factor $\kappa \mathrm{B}$ inhibitor parthenolide restores ICI 182,780 (Faslodex; fulvestrant)-induced apoptosis in antiestrogen-resistant breast cancer cells. Mol Cancer Ther 4: 33-41, 2005.

149. Schoenlein PV, Periyasamy-Thandavan S, Samaddar JS, Jackson WH and Barrett JT: Autophagy facilitates the progression of ER $\alpha$-positive breast cancer cells to antiestrogen resistance. Autophagy 5: 400-403, 2009.

150. Butt AJ, Sutherland RL and Musgrove EA: Live or let die: estrogen regulation of survival signalling in endocrine response. Breast Cancer Res 9: 306-309, 2007.

151. Gu Z, Lee RY, Skaar TC, Bouker KB, Welch JN, et al: Association of interferon regulatory factor-1, nucleophosmin, nuclear factor$\kappa \mathrm{B}$, and cyclic AMP response element binding with acquired resistance to Faslodex (ICI 182,780). Cancer Res 62: 3428-3437, 2002.

152. Gomez BP, Riggins RB, Shajahan AN, Klimach U, Wang A, et al: Human X-box binding protein-1 confers both estrogen independence and antiestrogen resistance in breast cancer cell lines. FASEB J 21: 4013-4027, 2007.

153. Davies MP, Barraclough DL, Stewart C, Joyce KA, Eccles RM, Barraclough R, Rudland PS and Sibson DR: Expression and splicing of the unfolded protein response gene XBP-1 are significantly associated with clinical outcome of endocrinetreated breast cancer. Int J Cancer 123: 85-88, 2008.
154.Zhu Y, Singh B, Hewitt S, Liu A, Gomez B, Wang A and Clarke R: Expression patterns among interferon regulatory factor-1, human X-box binding protein-1, nuclear factor kappa B, nucleophosmin, estrogen receptor-alpha and progesterone receptor proteins in breast cancer tissue microarrays. Int $\mathbf{J}$ Oncol 28: 67-76, 2006

155. Clarke R, Liu MC, Bouker KB, Gu Z, Lee RY, et al: Antiestrogen resistance in breast cancer and the role of estrogen receptor signalling. Oncogene 22: 7316-7339, 2003.

156. Thiery JP, Acloque H, Huang RYJ and Nieto MA: Epithelialmesenchymal transitions in development and disease. Cell 139: 871-890, 2009.

157. Gilles $\mathrm{C}$ and Thompson EW: The epithelial to mesenchymal transition and metastatic progression in carcinoma. Breast $\mathrm{J} 2$ : 83-96, 1996.

158. Greenberg G and Hay ED: Epithelia suspended in collagen gels can lose polarity and express characteristics of migrating mesenchymal cells. J Cell Biol 95: 333-339, 1982.

159. Huber MA, Azoitei N, Baumann B, Grünert S, Sommer A, et al: $\mathrm{NF}-\mathrm{kappaB}$ is essential for epithelial-mesenchymal transition and metastasis in a model of breast cancer progression. J Clin Invest 114: 569-581, 2004.

160. Tian F, DaCosta Byfield S, Parks WT, Yoo S, et al: Reduction in Smad2/3 signaling enhances tumorigenesis but suppresses metastasis of breast cancer cell lines. Cancer Res 63: 8284-8292, 2003.

161. Tarin D: The fallacy of epithelial mesenchymal transition in neoplasia. Cancer Res 65: 5996-6001, 2005.

162. Christiansen JJ and Rajasekaran AK: Reassessing epithelial to mesenchymal transition as a prerequisite for carcinoma invasion and metastasis. Cancer Res 66: 8319-8326, 2006.

163. Garber K: Epithelial-to-mesenchymal transition is important to metastasis, but questions remain. J Natl Cancer Inst 100: 232-239, 2008

164. Berx G, Raspe E, Christofori G, Thiery JP and Sleeman JP: Pre-EMTing metastasis: recapitulation of morphogenetic processes in cancer. Clin Exp Metastasis 24: 587-597, 2007.

165. Tse JC and Kalluri R: Mechanisms of metastasis: epithelial-tomesenchymal transition and contribution of tumor microenvironment. J Cell Biochem 101: 816-829, 2007.

166. Li GC and Wang ZY: Constitutive expression of RbAp46 induces epithelial-mesenchymal transition in mammary epithelial cells. Anticancer Res 26A: 3555-3560, 2006.

167. Blick T, Widodo E, Hugo H, Waltham M, Lenburg ME, Neve RM and Thompson EW: Epithelial mesenchymal transition traits in human breast cancer cell lines. Clin Exp Metastasis 25: 629-642, 2008.

168. Hennessy BT, Gonzalez-Angulo AM, Stemke-Hale K, Gilcrease MZ, Krishnamurthy S, Lee JS, et al: Characterization of a naturally occurring breast cancer subset enriched in epithelialto-mesenchymal transition and stem cell characteristics. Cancer Res 69: 4116-4124, 2009.

169. Trimboli AJ, Fukino K, de Bruin A, Wei G, Shen L, Tanner SM, et al: Direct evidence for epithelial-mesenchymal transitions in breast cancer. Cancer Res 68: 937-945, 2008.

170. Brabletz T, Jung A, Spaderna S, Hlubek F and Kirchner T: Migrating cancer stem cells - an integrated concept of malignant tumor progression. Nat Rev 5: 744-749, 2005.

171. Sphyris N and Mani SA: The importance of the epithelialmesenchymal transition in breast cancer. Curr Breast Cancer Rep 1: 229-237, 2009.

172. Sarrio D, Rodriguez-Pinilla SM, Hardisson D, Cano A, Moreno-Bueno G and Palacios J: Epithelial-mesenchymal transition in breast cancer relates to the basal-like phenotype. Cancer Res 68: 989-997, 2008

173. Wheelock MJ and Johnson KR: Cadherins as modulators of cellular phenotype. Annu Rev Cell Dev Biol 19: 207-235, 2003.

174. Onder TT, Gupta PB, Mani SA, Yang J, Lander ES and Weinberg RA: Loss of E-cadherin promotes metastasis via multiple downstream transcriptional pathways. Cancer Res 68 : 3645-3653, 2008

175. Berx G and van Roy F: The E-cadherin/catenin complex: an important gatekeeper in breast cancer tumorigenesis and malignant progression. Breast Cancer Res 3: 289-293, 2001.

176. Baranwal S and Alahari SK: Molecular mechanisms controlling E-cadherin expression in breast cancer. Biochem Biophys Res Commun 384: 6-11, 2009.

177. Kim S, Kang HY, Nam E-H, Choi M-S, Zhao X-F, et al: TMPRSS4 induces invasion and epithelial-mesenchymal transition through upregulation of integrin $\alpha 5$ and its signalling pathways. Carcinogenesis 31: 597-606, 2010 
178. Yang J, Mani SA, Donaher JL, Ramaswamy S, Itzykson RA, et al: Twist, a master regulator of morphogenesis, plays an essential role in tumour metastasis. Cell 117: 927-939, 2004.

179. Sarrio D, Palacios J, Hergueta-Redondo M, et al: Functional characterization of E- and P-cadherin in invasive breast cancer cells. BMC Cancer 9: 74-76, 2009.

180. Cheng CW, Wu PE, Yu JC, Huang CS, Yue CT, Wu CW and Shen CY: Mechanisms of inactivation of E-cadherin in breast carcinoma: modification of the two-hit hypothesis of tumor suppressor gene. Oncogene 20: 3814-3823, 2001.

181. Blanco MJ, Moreno-Bueno G, Sarrio D, Locascio A, Cano A, Palacios J and Nieto MA: Correlation of Snail expression with histological grade and lymph node status in breast carcinomas. Oncogene 21: 3241-3246, 2002.

182. Moody SE, Perez D, Pan TC, Sarkisian CJ, Portocarrero CP, Sterner CJ et al: The transcriptional repressor Snail promotes mammary tumour recurrence. Cancer Cell 8: 197-209, 2005.

183. Martin TA, Goyal A, Watkins G and Jiang WG: Expression of the transcription factors snail, slug, and twist and their clinical significance in human breast cancer. Ann Surg Oncol 12: 488-496, 2005.

184. Elloul S, Elstrand MB, Nesland JM, Trope CG, Kvalheim G, Goldberg I, Reich R and Davidson B: Snail, Slug, and Smadinteracting protein 1 as novel parameters of disease aggressiveness in metastatic ovarian and breast carcinoma. Cancer 103 1631-1643, 2005.

185. Wheelock MJ, Shintani Y, Maeda M, Fukumoto Y and Johnson KR: Cadherin switching. J Cell Sci 121: 727-732, 2008

186. Gjerdrum C, Tiron C, Høiby T, Stefansson I, Haugen H, et al: $\mathrm{Axl}$ is an essential epithelial-to-mesenchymal transition-induced regulator of breast cancer metastasis and patient survival. Proc Natl Acad Sci USA 107: 1124-1129, 2010.

187. Cano A, Perez-Moreno MA, Rodrigo I, Locascio A, Blanco MJ, et al: The transcription factor Snail controls epithelialmesenchymal transitions by repressing E-cadherin expression. Nat Cell Biol 2: 76-83, 2000.

188. Vandewalle C, Comijn J, De Craene B, Vermassen P, Bruyneel E, et al: SIP1/ZEB2 induces EMT by repressing genes of differen epithelial cell-cell junctions. Nucleic Acids Res 33: 6566-6578, 2005.

189. Hazan RB, Phillips GR, Qiao RF, Norton L and Aaronson SA: Exogenous expression of $\mathrm{N}$-cadherin in breast cancer cells induces cell migration, invasion, and metastasis. J Cell Biol 148 779-790, 2000.

190. Hazan Rb, Qiao R, Keren R, Badano I, and Suyama K: Cadherin switch in tumour progression. Ann NY Acad Sci 1014: 155-163, 2004

191. Luqmani YA, Al Mulla F and Al Saleh S: siRNA induced loss of estrogen receptor in human breast cancer cells is associated with an epithelial to mesenchymal transition. Int J Mol Med 26 (Suppl. 1): A140, 2010.

192. Berx G and van Roy F: Involvement of members of the cadherin superfamily in cancer. Cold Spring Harb Perspect Biol 1: a003129, 2009.

193. Kim K, Lu Z and Hay ED: Direct evidence for a role of $\beta$-catenin/LEF-1 signalling pathway in induction of EMT. Cell Biol Int 26: 463-476, 2002 .

194. Hiscox S, Jiang WG, Obermeier K, Taylor K, Morgan L, Burmi R, Barrow D and Nicholson RI: Tamoxifen resistance in MCF7 cells promotes EMT-like behaviour and involves modulation of $\beta$-catenin phosphorylation. Int $\mathrm{J}$ Cancer 118 290-301, 2006.

195. Aigner K, Dampier B, Descovich L, et al: The transcription factor ZEB1 (deltaEF1) promotes tumour cell dedifferentiation by repressing master regulators of epithelial polarity. Oncogene 26: 6979-6988, 2007

196. Kokkinos MA, Wafai R, Wong MK, Newgreen DF, Thompson EW and Waltham M: Vimentin and epithelial-mesenchymal transition in human breast cancer-observations in vitro and in vivo. Cells Tiss Organs 185: 191-203, 2007.

197. Pieper FR, Van de Klundert FA, Raats JM, et al: Regulation of vimentin expression in cultured epithelial cells. Eur J Biochem 210: 509-519, 1992

198. Gilles C, Polette M, Mestdagt M, et al: Transactivation of vimentin by beta-catenin in human breast cancer cells. Cancer Res 63: 2658-2664, 2003.

199. Al Saleh S: Association of functional loss of estrogen receptor with an epithelial to mesenchymal transition in human breast cancer. MSc thesis, Kuwait University, 2010.
200. Dandachi N, Hauser-Kronberger C, More E, et al: Co-expression of tenascin- $\mathrm{C}$ and vimentin in human breast cancer cells indicates phenotypic transdifferentiation during tumour progression: correlation with histopathological parameters, hormone receptors, and onco-proteins. J Pathol 193: 181-189, 2001.

201. Polette M, Mestdagt M, Bindels S, et al: Beta-catenin and ZO-1: shuttle molecules involved in tumor invasion-associated epithelial-mesenchymal transition processes. Cells Tiss Organs 185: 61-65, 2007.

202. Bindels S, Mestdagt M, Vandewalle C, et al: Regulation of vimentin by SIP1 in human epithelial breast tumor cells. Oncogene 25: 4975-4985, 2006.

203. Orlichenko LS and Radisky DC: Matrix metalloproteinases stimulate epithelial-mesenchymal transition during tumour development. Clin Exp Metastasis 25: 593-600, 2008

204. Yang J, Bielenberg Diane R. Rodig SJ, Doiron R, et al: Lipocalin 2 promotes breast cancer progression. Proc Natl Acad Sci USA 106: 3913-3918, 2009.

205. Wang X, Zheng M, Liu G, Xia W, McKeown-Longo PJ, Hung MC and Zhao J: Kruppel-like factor 8 induces epithelial to mesenchymal transition and epithelial cell invasion. Cancer Res 67: 7184-7193, 2007.

206. Guaita S, Puig I, Franci C, Garrido M, Dominguez D and Batelle E: Snail induction of epithelial to mesenchymal transition in tumor cells is accompanied by MUC1 repression and ZEB1 expression. J Biol Chem 277: 39209-39216, 2002.

207. Eger A, Aigner K, Sonderegger S, Dampier B, Oehler S, Schreiber M, et al: DeltaEF1 is a transcriptional repressor of E-cadherin and regulates epithelial plasticity in breast cancer cells. Oncogene 24: 2375-2385, 2005.

208. Spaderna S, Schmalhofer O, Hlubek F, Berx G, Eger A, Merkel S, et al: A transient, EMT-linked loss of basement membranes indicates metastasis and poor survival in colorectal cancer. Gastroenterology 131: 830-840, 2006.

209. Spaderna S, Schmalhofer O, Wahlbuhl M, Dimmler A, Bauer K, Sultan A, et al: The transcriptional repressor ZEB1 promotes metastasis and loss of cell polarity in cancer. Cancer Res 68: 537-544, 2008

210. Hollier BG, Evans K and Mani SA: The epithelial-to-mesenchymal transition and cancer stem cells: a coalition agains cancer therapies. J Mamm Gland Biol Neoplasia 14: 29-43, 2009.

211. Polyak K and Weinberg RA: Transitions between epithelial and mesenchymal states: acquisition of malignant and stem cell traits. Nat Rev Cancer 9: 265-273, 2009.

212. Lo HW, Hsu SC, Xia W, Cao X, Shih JY, et al: Epidermal growth factor receptor cooperates with signal transducer and activator of transcription 3 to induce epithelial-mesenchymal transition in cancer cells via up-regulation of Twist gene expression. Cancer Res 67: 9066-9076, 2007.

213. Yan W, Cao QJ, Arenas Rb, Bentley B and Shao R: GATA3 inhibits breast cancer metastasis through the reversal of epithelialmesenchymal transition. J Biol Chem 285: 14042-14051, 2010.

214. Hartwell KA, Muir B, Reinhardt F, et al: The Spemann organizer gene, Goosecoid, promotes tumor metastasis. Proc Natl Acad Sci USA 103: 18969-18974, 2006.

215. Sommers CL, Walker-Jones D, Heckford SE, Worland P, Valverius E, et al: Vimentin rather than keratin expression in some hormone-independent breast cancer cell lines and in oncogene-transformed mammary epithelial cells. Cancer Res 49: 4258-4263, 1989.

216. Carlsson P and Mahlapuu M: Forkhead transcription factors: key players in development and metabolism. Dev Biol 250: $1-23,2002$

217. Mani SA, Yang J, Brooks M, et al: Mesenchyme Forkhead 1 (FOXC2) plays a key role in metastasis and is associated with aggressive basal-like breast cancers. Proc Natl Acad Sci USA 104: 10069-10074, 2007.

218. Come C, Magnino F, Bibeau F, et al: Snail and slug play distinct roles during breast carcinoma progression. Clin Cancer Res 12: 5395-5402, 2006

219. Laffin B, Wellberg E, Kwak HI, et al: Loss of singleminded-2s in the mouse mammary gland induces an epithelial-mesenchymal transition associated with up-regulation of slug and matrix metalloprotease 2. Mol Cell Biol 28: 1936-1946, 2008.

220. Lester RD, Jo M, Montel V, et al: uPAR induces epithelial mesenchymal transition in hypoxic breast cancer cells. J Cell Biol 178: 425-436, 2007.

221. Storci G, Sansone P, Trere D, et al: The basal-like breast carcinoma phenotype is regulated by Slug gene expression. J Pathol 214: 25-37, 2008. 
222. Yang MH, Wu MZ, Chiou SH, Chen PM, Chang SY, Liu CJ, Teng SC and Wu KJ: Direct regulation of Twist by HIF-lalpha promotes metastasis. Nat Cell Biol 10: 295-305, 2008.

223. Linger RM, Keating AK, Earp HS and Graham DK: TAM receptor tyrosine kinases: biologic functions, signalling, and potential therapeutic targeting in human cancer. Adv Cancer Res 100: 35-83, 2008.

224.MGI Gene Expression Database: www.informatics.jax.org

225. Hafizi S and Dahlbäck B: Signaling and functional diversity within the Axl subfamily of receptor tyrosine kinases. Cytok Growth Factor Rev 17: 295-304, 2006.

226. Holland SJ, Powell MJ, Franci C, Chan EW, Friera AM, et al: Multiple roles for the receptor tyrosine kinase Axl in tumor formation. Cancer Res 65: 9294-9303, 2005.

227. Vajkoczy P, Knyazev P, Kunkel A, Capelle HH, Behrndt S, et al: Dominant-negative inhibition of the Axl receptor tyrosine kinase suppresses brain tumor cell growth and invasion and prolongs survival. Proc Natl Acad Sci USA 103: 5799-5804, 2006.

228. Arima Y, Inoue Y, Shibata T, Hayashi H, Nagano O, Saya H and Taya Y: Rb depletion results in deregulation of E-cadherin and induction of cellular phenotypic changes that are characteristic of the epithelial-to-mesenchymal transition. Cancer Res 68: 5104-5112, 2008

229. Liu M, Casimiro MC, Wang C, Shirley LA, Jiao X, et al: p21 ${ }^{\mathrm{CIP} 1}$ attenuates ras- and c-Myc-dependent breast tumor epithelial mesenchymal transition and cancer stem cell-like gene expression in vivo. Proc Natl Acad Sci USA 106: 19035-19039, 2009.

230. Lechner JF, Fugaro JM, Wong Y, Pass HI, Harris CC and Belinsky SA: Perspective: cell differentiation theory may advance early detection of and therapy for lung cancer. Radiat Res 155: 235-238, 2001.

231. Miller GJ, Miller HL, van Bokhoven A, et al: Aberrant HOXC expression accompanies the malignant phenotype in human prostate. Cancer Res 63: 5879-5888, 2003.

232. Naora H, Yang YQ, Montz FJ, Seidman JD, Kurman RJ and Roden Rb: A serologically identified tumor antigen encoded by a homeobox gene promotes growth of ovarian epithelial cells. Proc Natl Acad Sci USA 98: 4060-4065, 2001.

233. Yoshida H, Broaddus R, Cheng W, Xie S and Naora H: Deregulation of the HOXA10 homeobox gene in endometrial carcinoma: role in epithelial-mesenchymal transition. Cancer Res 66: 889-897, 2006.

234. Raman V, Martensen SA, Reisman D, et al: Compromised HOXA5 function can limit p53 expression in human breast tumours. Nature 405: 974-978, 2000.

235. Chen H, Chung S and Sukumar S: HOXA5-induced apoptosis in breast cancer cells is mediated by caspases 2 and 8 . Mol Cell Biol 24: 924-935, 2004.

236. Carrio M, Arderiu G, Myers C and Boudreau NJ: Homeobox D10 induces phenotypic reversion of breast tumor cells in a threedimensional culture model. Cancer Res 65: 7177-7185, 2005

237. Ma XJ, Wang Z, Ryan PD, et al: A two-gene expression ratio predicts clinical outcome in breast cancer patients treated with tamoxifen. Cancer Cell 5: 607-616, 2004.

238. Srebrow A, Friedmann Y, Ravanpay A, Daniel CW and Bissell MJ: Expression of Hoxa-1 and Hoxb-7 is regulated by extracellular matrix-dependent signals in mammary epithelial cells. J Cell Biochem 69: 377-391, 1998.

239. Care A, Silvani A, Meccia E, Mattia G, Peschle C and Colombo MP: Transduction of the $\mathrm{SkBr} 3$ breast carcinoma cell line with the HOXB7 gene induces bFGF expression, increases cell proliferation and reduces growth factor dependence. Oncogene 16: 3285-3289, 1998.

240. Care A, Felicetti F, Meccia E, et al: HOXB7: a key factor for tumor-associated angiogenic switch. Cancer Res 61: 6532-6539, 2001.

241. Hyman E, Kauraniemi P, Hautaniemi S, et al: Impact of DNA amplification on gene expression patterns in breast cancer. Cancer Res 62: 6240-6245, 2002.

242. Hayashida T, Takahashi F, Chiba N, Brachtel E, Takahashi M, et al: $\operatorname{HOXB} 9$, a gene overexpressed in breast cancer, promotes tumorigenicity and lung metastasis. Proc Natl Acad Sci USA 107: $1100-1105,2010$

243. McCoy EL, Iwanaga R, Jedlicka P, Abbey NS, Chodosh LA, Heichman KA, Welm AL and Ford HL: Six1 expands the mouse mammary epithelial stem/progenitor cell pool and induces mammary tumors that undergo epithelial-mesenchymal transition. J Clin Invest 119: 2663-2677, 2009.
244. Micalizzi DS, Christensen KL, Jedlicka P, Coletta RD, Barón AE, et al: The Six1 homeoprotein induces human mammary carcinoma cells to undergo epithelial-mesenchymal transition and metastasis in mice through increasing TGF- $\beta$ signaling. J Clin Invest 119: 2678-2690, 2009.

245. Wu Y, Deng J, Rychahou PG, et al: Stabilization of snail by NF-kappaB is required for inflammation-induced cell migration and invasion. Cancer Cell 15: 416-428, 2009.

246. Sullivan NJ, Sasser AK, Axel AE, et al: Interleukin-6 induces an epithelial-mesenchymal transition phenotype in human breast cancer cells. Oncogene 28: 2940-2947, 2009.

247. Hiscox S, Morgan L, Green TP, Barrow D, Gee J and Nicholson RI: Elevated src activity promotes cellular invasion and motility in tamoxifen resistant breast cancer cells. Breast Cancer Res Treat 97: 263-274, 2006.

248. Hiscox S, Borley A, Nicholson RI and Barett-Lee P: Epithelialmesenchymal transition (EMT) and its involvement in acquired endocrine resistance in breast cancer. Chapter 5. In: Cancer Drug Resistance Research perspectives. Torres LS (ed.) Nova Science Publishers, New York, pp81-95, 2007.

249. Asselin-Labat ML, Shackleton M, Stingl J, Vaillant F, Forrest NC, Eaves CJ, Visvader JE and Lindeman GJ: Steroid hormone receptor status of mouse mammary stem cells. J Natl Cancer Inst 98: 1011-1014, 2006.

250. Hebbard L, Steffen A, Zawadzki V, Fieber C, Howells N, et al: CD44 expression and regulation during mammary gland development and function. J Cell Sci 113: 2619-2630, 2000.

251. Clarke RB, Howell A, Potten CS and Anderson E: Dissociation between steroid receptor expression and cell proliferation in the human breast. Cancer Res 57: 4987-4991, 1997.

252. Sleeman KE, Kendrick H, Robertson D, Isacke CM, Ashworth A and Smalley MJ: Dissociation of estrogen receptor expression and in vivo stem cell activity in the mammary gland. J Cell Biol 176: 19-26, 2007.

253. Shipitsin M, Campbell LL, Argani P, Weremowicz S, Bloushtain-Qimron N, et al: Molecular definition of breast tumor heterogeneity. Cancer Cell 11: 259-273, 2007.

254. Ginestier C, Hur MH, Charafe-Jauffret E, Monville F, Dutcher J, et al: ALDH1 is a marker of normal and malignant human mammary stem cells and a predictor of poor clinical outcome. Cell Stem Cell 1: 555-567, 2007.

255. Magnifico A, Albano L, Campaner S, Delia D, Castiglioni F, et al: Tumor-initiating cells of HER2-positive carcinoma cell lines express the highest oncoprotein levels and are Trastuzumab sensitive. Clin Cancer Res 15: 2010-2021, 2009.

256. Li X, Lewis MT, Huang J, Gutierrez C, Osborne CK, Wu MF, et al: Intrinsic resistance of tumorigenic breast cancer cells to chemotherapy. J Natl Cancer Inst 100: 672-679, 2008.

257. Yu F, Yao H, Zhu P, Zhang X, Pan Q, et al: let-7 regulates self renewal and tumorigenicity of breast cancer cells. Cell 131: 1109-1123, 2007.

258. Shackleton M, Vaillant F, Simpson KJ, Stingl J, Smyth GK, et al: Generation of a functional mammary gland from a single stem cell. Nature 439: 84-88, 2006.

259. Osipo C, Patel P, Rizzo P, Clementz AG, Hao L, Golde TE and Miele L: ErbB-2 inhibition activates Notch-1 and sensitizes breast cancer cells to a gamma-secretase inhibitor. Oncogene 27: 5019-5032, 2008

260. Borley AC, Hiscox S, Gee J, Smith C, Shaw V, Barrett-Lee P and Nicholson RI: Anti-estrogens but not estrogen deprivation promote cellular invasion in intercellular adhesion-deficient breast cancer cells. Breast Cancer Res 10: R103, 2008.

261. Elliott BE, Hung WL, Boag AH and Tuck AB: The role of hepatocyte growth factor (scatter factor) in epithelial-mesenchymal transition and breast cancer. Can J Physiol Pharmacol 80: 91-102, 2002.

262. Mani SA, Guo W, Liao MJ, Eaton EN, Ayyanan A, et al: The epithelial-mesenchymal transition generates cells with properties of stem cells. Cell 133: 704-715, 2008.

263. Al-Hajj M, Wicha MS, Benito-Hernandez A, et al: Prospective identification of tumorigenic breast cancer cells. Proc Natl Acad Sci USA 100: 3983-3988, 2003.

264. Morel AP, Lievre M, Thomas C, et al: Generation of breast cancer stem cells through epithelial-mesenchymal transition. PLoS One 3: e2888, 2008.

265. Santisteban M, Reiman JM, Asiedu MK, et al: Immune-induced epithelial to mesenchymal transition in vivo generates breast cancer stem cells. Cancer Res 69: 2887-2895, 2009. 
266. DiMeo TA, Anderson K, Phadke P, et al: A novel lung metastasis signature links wnt signalling with cancer cell self-renewal and epithelial-mesenchymal transition in basal-like breast cancer. Cancer Res 69: 5364-5373, 2009.

267. Fillmore CM and Kuperwasser C: Human breast cancer cell lines contain stem-like cells that self-renew, give rise to phenotypically diverse progeny and survive chemotherapy. Breast Cancer Res 10: R25, 2008

268. Dhasarathy A, Kajita M and Wade PA: The transcription factor snail mediates epithelial to mesenchymal transitions by repression of estrogen receptor-alpha. Mol Endocrinol 21: 2907-2918, 2007.

269. Ye Y, Xiao Y, Wang W, Yearsley K, Gao JX and Barsky SH: ERalpha suppresses slug expression directly by transcriptional repression. Biochem J 416: 179-187, 2008.

270. Tomaskovic-Crook E, Thompson EW and Thiery JP: Epithelial to mesenchymal transition and breast cancer. Breast Cancer Res 11: 213-223, 2009.

271. Li QQ, Xu JD, Wang WJ, Cao XX, Chen Q, et al: Twist1-mediated adriamycin-induced epithelial mesenchymal transition relates to multidrug resistance and invasive potential in breast cancer cells. Clin Cancer Res 15: 2657-2665, 2009.

272. Bedard PL, De Azambuja E and Cardoso F: Beyond trastuzumab: overcoming resistance to targeted HER-2 therapy in breast cancer Curr Cancer Drug Targets 9: 148-162, 2009.

273. Gupta PB, Onder TT, Jiang G, Tao K, Kuperwasser C, Weinberg RA and Lander ES: Identification of selective inhibitors of cancer stem cells by high-throughput screening. Cell 138 645-659, 2009.

274. Al Azmi A: Estrogen receptor gene silencing in breast cancer cells using siRNA. MSc thesis, Kuwait University, 2006.

275. Luqmani YA, Al Azmi A, Al Bader M, Abraham G and El Zawahri M: Modification of gene expression induced by siRNA targeting of estrogen receptor in MCF7 human breast cancer cells. Int J Oncol 34: 231-242, 2009.

276. Al Saleh S and Luqmani YA: Effect of tyrosine kinase inhibitors is enhanced in endocrine-resistant breast cancer cells displaying increased metastatic potential. Proc 15th World Congress on Advances in Oncology and 13th International Symposium on Molecular Medicine. Int J Mol Med 26 (Suppl. 1): A141, 2010.

277. Parker KP, Brock AL, Brangwyyne C, Mannix RJ, Wang N, et al: Directional control of lamellipodial extension by constraining cell shape and orienting cell tractional forces. FASEB J 16 : 1195-1204, 2002

278. Zajchowski DA, Bartholdi MF, Gong Y, Webster L, Liu HL, et al: Identification of gene expression profiles that predict the aggressive behaviour of breast cancer cells. Cancer Res 61: 5168-5178, 2001.

279. Thompson EW, Newgreen DF and Tarin D: Carcinoma invasion and metastasis: a role for epithelial-mesenchymal transition? Cancer Res 65: 5991-5995, 2005.
280. Willipinski-Stapelfeldt B, Riethdorf S, Assmann V, et al: Changes in cytoskeletal protein composition indicative of an epithelial-mesenchymal transition in human micrometastatic and primary breast carcinoma cells. Clin Cancer Res 11: 8006-8014, 2005.

281. Das S, Becker B, Hoffmann FM and Mertz JE: Complete reversal of epithelial to mesenchymal transition requires inhibition of both ZEB expression and the Rho pathway. BMC Cell Biol 10: $94-112,2009$.

282. Derynck R and Zhang YE: Smad-dependent and Smadindependent pathways in TGF-beta family signalling. Nature 425: 577-584, 2003.

283. Ozdamar B, Bose R, Barrios-Rodiles M, Wang HR, Zhang Y and Wrana JL: Regulation of the polarity protein Par6 by TGFbeta receptors controls epithelial cell plasticity. Science 307: 1603-1609, 2005.

284. Gryfe R, Kim H, Hsieh ET, et al: Tumor microsatellite instability and clinical outcome in young patients with colorectal cancer. N Engl J Med 342: 67-69, 2000.

285. Deckers M, van Dinther M, Buijs J, Que I, Lowik C, van der Pluijm Gabri and ten Dijke P: The tumor suppressor Smad4 is required for transforming growth factor B-induced epithelial to mesenchymal transition and bone metastasis of breast cancer cells. Cancer Res 66: 2202-2209, 2006.

286. Xue C, Plieth D, Venkov C, et al: The gatekeeper effect of epithelial-mesenchymal transition regulates the frequency of breast cancer metastasis. Cancer Res 63: 3386-3394, 2003.

287. Andreasen PA, Kjoller L, Christensen L and Duffy MJ: The urokinase-type plasminogen activator system in cancer metastasis: a review. Int J Cancer 72: 1-22, 1997.

288. Schmitt M, Harbeck N, Thomssen C, Wilhelm O, Magdolen V, et al: Clinical impact of the plasminogen activation system in tumor invasion and metastasis: prognostic relevance and target for therapy. Thromb Haemost 78: 285-296, 1997.

289. Stephens RW, Brunner N, Janicke F and Schmitt M: Theurokinase plasminogen activator system as a target for prognostic studies in breast cancer. Breast Cancer Res Treat 52: 99-111, 1998.

290. Foekens JA, Peters HA, Look MP, et al: The urokinase system of plasminogen activation and prognosis in 2780 breast cancer patients. Cancer Res 60: 636-643, 2000.

291. De Cremoux P, Grandin L, Diéras V, Savignoni A, Degeorges A et al: Urokinase-type plasminogen activator and plasminogenactivator-inhibitor type 1 predict metastases in good prognosis breast cancer patients. Anticancer Res 29: 1475-1482, 2009.

292. Jo M, Lester RD, Montel V, Eastman B, Takimoto S and Gonias SL: Reversibility of epithelial-mesenchymal transition (EMT) induced in breast cancer cells by activation of urokinase receptor-dependent cell signaling. J Biol Chem 284: 22825-22833, 2009. 